\title{
Hydroxytyrosol prevents reduction in liver activity of $\Delta-5$ and $\Delta-6$ desaturases, oxidative stress, and depletion in long chain polyunsaturated fatty acid content in different tissues of high-fat diet fed mice
}

\author{
Rodrigo Valenzuela ${ }^{1,2^{*}}$, Francisca Echeverria', Macarena Ortiz ${ }^{1}$, Miguel Ángel Rincón-Cervera ${ }^{2}$, Alejandra Espinosa ${ }^{3}$,
} María Catalina Hernandez-Rodas ${ }^{1}$, Paola Illesca ${ }^{4}$, Alfonso Valenzuela ${ }^{2}$ and Luis A. Videla ${ }^{5}$

\begin{abstract}
Background: Eicosapentaenoic acid (EPA, C20:5n-3), docosahexaenoic acid (DHA, C22:6n-3) and arachidonic acid (AA, C20:4n-6) are long-chain polyunsaturated fatty acids (LCPUFAs) with relevant roles in the organism. EPA and DHA are synthesized from the precursor alpha-linolenic acid (ALA, C18:3n-3), whereas AA is produced from linoleic acid (LA, C18:2n-6) through the action of $\Delta 5$ and $\Delta 6$-desaturases. High-fat diet (HFD) decreases the activity of both desaturases and LCPUFA accretion in liver and other tissues. Hydroxytyrosol (HT), a natural antioxidant, has an important cytoprotective effects in different cells and tissues.

Methods: Male mice C57BL/6 J were fed a control diet (CD) (10\% fat, 20\% protein, 70\% carbohydrates) or a HFD (60\% fat, 20\% protein, 20\% carbohydrates) for 12 weeks. Animals were daily supplemented with saline (CD) or $5 \mathrm{mg}$ HT (HFD), and blood and the studied tissues were analyzed after the HT intervention. Parameters studied included liver histology (optical microscopy), activity of hepatic desaturases 5 and 6 (gas-liquid chromatography of methyl esters derivatives) and antioxidant enzymes (catalase, superoxide dismutase, glutathione peroxidase, and glutathione reductase by spectrophotometry), oxidative stress indicators (glutathione, thiobarbituric acid reactants, and the antioxidant capacity of plasma), gene expression assays for sterol regulatory element-binding protein 1c (SREBP-1c) (qPCR and ELISA), and LCPUFA profiles in liver, erythrocyte, brain, heart, and testicle (gas-liquid chromatography).

Results: HFD led to insulin resistance and liver steatosis associated with SREBP-1c upregulation, with enhancement in plasma and liver oxidative stress status and diminution in the synthesis and storage of n- 6 and n-3 LCPUFAs in the studied tissues, compared to animals given control diet. HT supplementation significantly reduced fat accumulation in liver and plasma as well as tissue metabolic alterations induced by HFD. Furthermore, a normalization of desaturase activities, oxidative stress-related parameters, and tissue n-3 LCPUFA content was observed in HT-treated rats over control animals.

(Continued on next page)
\end{abstract}

\footnotetext{
* Correspondence: rvalenzuelab@med.uchile.cl

${ }^{1}$ Nutrition Department, Faculty of Medicine, University of Chile,

Independencia 1027, Casilla, 70000 Santiago 7, Chile

${ }^{2}$ Lipid Center, Institute of Nutrition and Food Technology (INTA), University

of Chile, Santiago, Chile

Full list of author information is available at the end of the article
} 
(Continued from previous page)

Conclusions: $\mathrm{HT}$ supplementation prevents metabolic alterations in desaturase activities, oxidative stress status, and n-3 LCPUFA content in the liver and extrahepatic tissues of mice fed HFD.

Keywords: Hydroxytyrosol, Oxidative stress, Antioxidant capacity, $\Delta 5 / \Delta 6$ Desaturase activity, LCPUFA, Liver and extrahepatic tissues

\section{Background}

Linoleic acid (LA, C18:2n-6) and alpha-linolenic acid (ALA, C18:3n-3) are essential polyunsaturated fatty acids (PUFA) for humans and other mammals because they lack the enzymatic machinery to synthesize these fatty acids (FAs) [1]. These PUFAs have important biochemical and physiological functions in the body [2], in addition of being the metabolic precursors of $n-6$ and $\mathrm{n}-3$ long-chain polyunsaturated fatty acids (LCPUFAs) [3]. LA is the precursor of n-6 LCPUFAs including arachidonic acid (AA, C20:4 n-6), the main metabolic product due to its relevant role in the development of visual and central nervous system and in the control of vascular homeostasis and inflammatory responses [4]. ALA is the precursor of the n-3 LCPUFAs eicosapentaenoic acid (EPA, C20:5n-3) and docosahexaenoic acid (DHA, C22:6n-3), metabolic products that have a number of functions in the body [5]. EPA is involved in the control of vascular homeostasis and resolution of the inflammatory responses [6], whereas DHA has a key role in brain and visual development [7] and in the protection of central and peripheral nervous system [8]. Synthesis of n-6 and n-3 LCPUFA from LA and ALA occurs mainly in the liver through a complex process of elongation and desaturation reactions to yield AA, EPA, and DHA [9], $\Delta-5$ and $\Delta-6$ desaturase representing the most relevant enzymes in LCPUFA biosynthesis, with $\Delta-6$ desaturase being the limiting enzyme of the process [10]. The activity and the expression of both desaturases are regulated by hormones such as insulin and estrogens and by the intracellular redox state [11, 12], and are subjected to polymorphisms resulting in alteration of tissue n-6 and n-3 LCPUFA levels [13]. A significant decrease in the activity of $\Delta-5$ and $\Delta-6$ desaturases has been reported in pathological conditions such as nonalcoholic liver steatosis in humans [14] and in mice subjected to a high-fat diet (HFD) [15], together with a depletion of tissue levels of n-6 and n-3 LCPUFA. Such effects may be mediated by oxidative stress of nutritional origin and by development of insulin resistance $[14,15]$.

Hydroxytyrosol (HT) is a polyphenol with antioxidant properties found in extra virgin olive oil (EVOO), which together with other components such as polyphenols (for instance tyrosol and oleuropein) and flavonoids support the relevant healthy properties of EVOO [16]. These include the cardio-protective, anti-inflammatory, anti-cancer, and antimicrobial actions of EVOO [16], characteristics that qualify EVOO as a healthy food. HT has shown protective effects at cellular and tissue levels, preventing endothelial cells from damage induced by reactive oxygen species (ROS) [17] and reducing endothelial damage and atherogenic injuries [18]. Different studies have demonstrated the protective effect of HT by (i) preventing LDL oxidation; (ii) inhibiting platelet aggregation; (iii) attenuating mitochondrial abnormalities, with HFD-induced metabolic syndrome prevention [19], and (iv) producing anti-inflammatory effects in association with a decreased activity of the enzymes cyclooxygenase 1 (COX1) and COX2 [20]. One of the main mechanisms underlying the cytoprotective properties of HT is the regulation of different signaling pathways associated to the intracellular redox state [21]. Given this background, the objective of this study was to evaluate the protective effects of HT on the changes induced by a HFD on (i) liver $\Delta-5$ and $\Delta-6$ desaturase enzyme activity and mRNA expression; (ii) plasma and liver oxidative stress-related parameters; and (iii) $n-6$ and n-3 LCPUFA deposition in liver and extrahepatic tissues of mice fed a HFD.

\section{Methods}

\section{Animal preparation and supplementation with HT}

Weaning male C57BL/6 J mice weighing 12-14 g (Bioterio Central, ICBM, Faculty of Medicine, University of Chile) were randomly assigned to each experimental group (four) and allowed free access to a control diet (CD) or a HFD. CD (expressed as \% total calories) was $10 \% \mathrm{Kcal}$ as fat, $20 \% \mathrm{Kcal}$ as protein, and $70 \% \mathrm{Kcal}$ as carbohydrate, with a caloric value of $3.85 \mathrm{kcal} / \mathrm{g}$ and free of EPA and DHA. HFD was $60 \% \mathrm{Kcal}$ as fat, $20 \% \mathrm{Kcal}$ as protein, and $20 \% \mathrm{Kcal}$ as carbohydrate, with a caloric value of $5.24 \mathrm{kcal} / \mathrm{g}$ and free of EPA and DHA (Research Diet INC, Rodent Diet, Product data D12450K and 12492, USA). Fatty acid composition of CD and HFD was previously published [15]. Compositions of the diets are shown in Additional file 1: Table S1. Animals were housed on a $12 \mathrm{~h}$ light/dark cycle from day 1 to 84 (12 weeks) and were provided water ad libitum. Supplemented groups received $5 \mathrm{mg}$ HT/day (elaVida ${ }^{\mathrm{TM}}$, DSM Nutritional Products Company, Nederland) by oral administration, and control groups received an isovolumetric amount of saline, thus comprising four experimental 
groups: (a) CD, (b) CD + HT, (c) HFD, and (d) HFD + HT. Weekly controls of body weight and diet intake were performed through the whole period. At the end of the 12th week, animals were fasted (6-8 h), anesthetized with isoflurane, and blood samples were obtained by cardiac puncture for the determination of aspartate transaminase (AST), alanine transaminase (ALT), glucose, insulin, triacylglycerols, total cholesterol, LDL-cholesterol, HDLcholesterol, thiobarbituric acid reactants (TBARs), and antioxidant capacity. Blood, liver, brain, heart, and testicle samples were frozen in liquid nitrogen for the determination of FA profiles. Liver samples were also fixed in phosphate-buffered formalin, embedded in paraffin, stained with haematoxylin-eosin and analysed by optical microscopy in a blind fashion for describing the presence of steatosis. The degree of steatosis was graded based on an established according to Brunt et al. [22]. Macrovesicular steatosis was graded on a scale $0-3$ based on the percentage of hepatocytes affected in each specimen. The score was 0 for none; 1 for up to 33\%; 2 for 33-66\%; and 3 for more than $66 \%$.

\section{Measurements of serum parameters and fat content in liver}

Serum glucose $(\mathrm{mM})$, total cholesterol $(\mathrm{mg} / 100 \mathrm{~mL})$, LDL-cholesterol (mg/100 mL), HDL-cholesterol (mg/ $100 \mathrm{~mL}$ ) and triacylglycerol levels $(\mathrm{mg} / \mathrm{dL})$ were measured using specific diagnostic kits (Wiener Lab, Argentina). A commercial immunoassay kit for mice serum insulin assessment $(\mu \mathrm{U} / \mathrm{mL})$ was used, according to the manufacturer's instructions (Mercodia, Uppsala, Sweden). Insulin resistance was estimated by the homeostasis model assessment method (HOMA) [fasting insulin $(\mu \mathrm{U} / \mathrm{mL}) \times$ fasting glucose $(\mathrm{mM}) / 22.5$ ] [23]. Serum AST and ALT activities (units/L) were measured using specific diagnostic kits (Biomerieux SA, Marcy L'Etoile, France).

\section{Assay for oxidative stress-related parameters in liver and plasma}

Livers from anesthetized animals were perfused in situ with a cold solution containing $150 \mathrm{mM} \mathrm{KCl}$ and $5 \mathrm{mM}$ Tris ( $\mathrm{pH} 7.4$ ) to remove blood for glutathione assessments. Reduced glutathione (GSH) and glutathione disulfide (GSSG) contents were assessed with an enzymatic recycling method [24]. Specific kits (Cayman Chemical Company, Ann Harbor, MI, USA) were used to measure contents of TBARs in liver and plasma and the antioxidant capacity of plasma according to the manufacturer's instructions.

\section{Determination of liver $\Delta-5$ and $\Delta-6$ desaturase activities}

Liver samples frozen in liquid nitrogen $(500 \mathrm{mg})$ were homogenized in a buffer solution $\mathrm{pH} 7.9$ containing $10 \mathrm{mmol} / \mathrm{L}$ HEPES, $1.0 \mathrm{mmol} / \mathrm{L}$ EDTA, 0.6\% Nonidet
P-40, $150 \mathrm{mmol} / \mathrm{L} \mathrm{NaCl}$, and protease inhibitors ( $1 \mathrm{mmol} / \mathrm{L}$ phenylmethylsulfonyl fluoride, $1 \mu \mathrm{g} / \mathrm{mL}$ aprotinin, $1 \mu \mathrm{g} / \mathrm{mL}$ leupeptin, and $1 \mathrm{mmol} / \mathrm{L}$ orthovanadate). Liver homogenates were centrifuged at $4{ }^{\circ} \mathrm{C}$, first at $2,000 \mathrm{~g}$ for $30 \mathrm{~s}$, followed by centrifugation of the supernatants at 5,000 $\mathrm{g}$ for $5 \mathrm{~min}$, and finally at 100,000 $\mathrm{g}$ for $60 \mathrm{~min}$, to obtain the extracts for the assessment of desaturase activities. $\Delta-5$ desaturase activity was determined by the amount of dihomo-gamma-linolenic acid (DHGLA, C20:3n-6) converted to AA. $\Delta-6$ desaturase activity was obtained by measuring the amount of gamma-linolenic acid (GLA, C18:3n-6) produced from LA, using albumin-bound FA precursors (DHGLA and LA) [25]. Desaturase activity was assayed using $1 \mathrm{~mL}$ of incubation medium containing $4 \mu \mathrm{mol}$ ATP, $0.1 \mu \mathrm{mol}$ coenzyme-A, $1.28 \mu \mathrm{mol} N \mathrm{NADH}, 2.42 \mu \mathrm{mol} N$-acetylcysteine, $0.5 \mu \mathrm{mol}$ nicotinamide, $5 \mu \mathrm{mol} \mathrm{MgCl}_{2}, 62.5 \mu \mathrm{mol}$ $\mathrm{NaF}$, and $62.5 \mu \mathrm{mol}$ phosphate buffer $\mathrm{pH} 7$, supplemented with $100 \mathrm{nmol}$ albumin-bound FA precursor and $1 \mathrm{mg}$ protein of cytosolic extract in a total volume of $100 \mu \mathrm{L}$, incubated at $37{ }^{\circ} \mathrm{C}$ for $30 \mathrm{~min}$ with shaking. $\Delta-5$ and $\Delta-6$ desaturase assays were conducted simultaneously. The reaction was stopped by adding $6 \mathrm{~mL}$ of a methanol:chloroform mixture $(2: 1 \mathrm{v} / \mathrm{v})$. Heptadecanoic acid $(17: 0$; purity $\geq 99 \%)$ was added $(20 \mu \mathrm{g})$ as internal standard. To determine the levels of products or precursors achieved after incubation, lipids were extracted and derivatized to FA methyl esters (FAME), which were analyzed by gas-liquid chromatographic as described previously [26]. FAME peaks were identified and quantified by comparison with a FAME standard mix (Nu-Chek Prep Inc, Elysian MN, USA). $\Delta-5$ and $\Delta-6$ desaturase activities were measured as net increase in DHGLA and GLA production, respectively, from the gas-liquid chromatography results and calculated from the differences between baseline values and those obtained after $30 \mathrm{~min}$ incubation. Results were expressed as nmol.mg protein ${ }^{-1} \cdot \mathrm{min}^{-1}$.

\section{Gene expression assays}

Total RNA was isolated from liver samples using Trizol (Invitrogen, Paisley, United Kingdom), according to the supplier's protocols. Purified RNA $(2 \mu \mathrm{g})$ was then treated with DNasa (DNA free kit; Ambion, Austin, TX, USA) and used to generate first-strand cDNA with M-MLV reverse transcriptase (Invitrogen), using random hexamers (Invitrogen, Paisley, United Kingdom) and dNTP mix (Bioline, London, United Kingdom), according to the manufacturer's protocol. The resultant cDNA was amplified with specific primer for mice in a total volume of $10 \mu \mathrm{L}$. Gene specific primer sequences used are shown in Additional file 1: Table S2. Primers were optimized to yield $95 \%-100 \%$ of reaction efficiency with PCR products by development in agarose gel to verify 
the correct amplification length. Real Time PCR was performed in a Strategen Mx3000P System (Agilent Technologies, California, USA) following the manufacturer's recommendation (Applied Biosystems, Foster City, CA, USA). All the expression levels of the target genes under study were normalized by the expression of $\beta$-actin as internal control (Applied Biosystems, Foster City, CA, USA). Fold changes between groups was calculated by the $2\left(^{-\Delta \Delta \mathrm{Ct}}\right)$ method.

\section{Assessment of liver sterol regulatory element-binding protein 1c (SREBP-1c) DNA-binding activity}

Nuclear extracts from liver tissue (left lobe) were obtained using a commercial extraction kit (Cayman Chemical Company, Item 10011223, Ann Arbor, MI, USA). SREBP-1c DNA-binding activity was assessed with a commercial ELISA kit (Cayman Chemical Company, Item 10010854) and according to the manufacturer's instructions. Values were expressed as percentage of SREBP-1c DNA-binding with respect to a positive control provided by the ELISA kit.

\section{Determination of liver catalase, superoxide dismutase, glutathione peroxidase, and glutathione reductase activities}

Liver samples were homogenized in three volumes of $30 \mathrm{mM}$ phosphate buffer, $\mathrm{pH} 7.4$, containing EDTA $(1 \mathrm{mM})$ and sucrose $(250 \mathrm{mmol})$. After centrifugation for $10 \mathrm{~min}$ at $1200 \mathrm{~g}$ and $4{ }^{\circ} \mathrm{C}$, one aliquot of the supernatant was used for the determination of both catalase (CAT) and superoxide dismutase (SOD) activities. Another aliquot was centrifuged at $100,000 \mathrm{~g}$ for $60 \mathrm{~min}$ at $4{ }^{\circ} \mathrm{C}$ to carry out glutathione peroxidase (GPX) and glutathione reductase (GR) assays according to Chow [27]. CAT activity was measured according to Lück [28]. Enzyme unit is defined as the amount of oxygen liberated from a hydrogen peroxide solution in $100 \mathrm{~s}$ at $25^{\circ} \mathrm{C}$. Assessment of SOD activity was carried out with a commercial assay kit (Cayman Chemical Company, Ann Arbor, MI, USA) according to the manufacturer's instructions. GPX activity was determined using hydrogen peroxide as substrate according to the method of Plagia and Valentine [29]. Enzyme activity was evaluated at $340 \mathrm{~nm}$ by measuring the decrease in the absorbance of NADPH. Enzyme unit is defined as the number of $\mu$ moles of $\mathrm{NADPH}$ oxidized per min at $20{ }^{\circ} \mathrm{C}$. GR activity was determined by the method of Horn [30]. Enzyme unit is defined as the amount of enzyme that reduces $1 \mu \mathrm{mol}$ of GSSG per min at $\mathrm{pH} 6.6$ and $25^{\circ} \mathrm{C}$.

\section{Lipid extraction and fractionation}

Quantitative extraction and separation of total lipids from liver, erythrocytes, brain, heart, and testicle was carried out according Bligh and Dyer [31]. Erythrocytes and tissue samples were homogenized in ice-cold chloroform/methanol $(2: 1 \mathrm{v} / \mathrm{v})$ containing $0.01 \%$ butylated hydroxytoluene (BHT). Total lipids from erythrocytes were extracted with chloroform/isopropanol (2:1 v/ v). Phospholipids from liver, erythrocytes, brain, heart, and testicle were separated from total lipid extracts by thin layer chromatography (TLC) on silica gel plates (aluminium sheets 20x20 cm, silica gel 60 F-254 (Merck, Santiago, Chile), using hexane/diethyl ether/acetic acid (80:20:1 v/v/v) as mobile phase. After development and solvent evaporation, lipid spots were visualized by exposing the plates to a Camag UV $(250 \mathrm{~nm})$. The solvent system allows the separation of phospholipids, cholesterol, triacylglycerols and cholesterol ester according to their relative mobility. Phospholipid spots were extracted from the silica with chloroform/methanol (2:1 v/v), according to Ruiz-Gutierrez et al. [32].

\section{Fatty acid analysis}

FAME from liver, erythrocytes, brain, heart, and testicle phospholipids were prepared with boron trifluoride according to Morrison and Smith [33], and a sodium hydroxide solution $(0.5 \mathrm{~N})$ in methanol. Phospholipids were extracted from the silica gel spots with $15 \mathrm{~mL}$ of chloroform/methanol/water (10:10:1) and solvents were then evaporated under nitrogen stream prior to derivatization of phospholipids to produce FAMEs. Samples were cooled and extracted with $0.5 \mathrm{~mL}$ of hexane. FAMEs were separated and quantified by gas-liquid chromatography in an Agilent Hewlett-Packard equipment (model 7890A, CA, USA) using a capillary column (Agilent HP-88, $100 \mathrm{~m}$ x $0.250 \mathrm{~mm}$; I.D. $0.25 \mu \mathrm{m}$ ) and a flame ionization detector (FID). Injector temperature was set at $250{ }^{\circ} \mathrm{C}$ and FID temperature at $300{ }^{\circ} \mathrm{C}$. Oven temperature was initially set at $140{ }^{\circ} \mathrm{C}$ and programmed to increase to $220{ }^{\circ} \mathrm{C}$ at a rate of $5{ }^{\circ} \mathrm{C} / \mathrm{min}$. Hydrogen was used as the carrier gas $(35 \mathrm{~cm} / \mathrm{s}$ flow rate) and the inlet split ratio was set at 20:1. Identification and quantification of FAMEs were achieved by comparing the retention times and the peak area values (\%) of the unknown samples with those of a commercial lipid standard (Nu-Chek Prep Inc, Elysian MN, USA). C23:0 was used as internal standard $(\mathrm{Nu}-\mathrm{Chek}$ Prep Inc, Elysian MN, USA) and a Hewlett-Packard Chemstation (Palo Alto, CA, USA) data system was used for processing.

\section{Statistical analysis}

Statistical analysis was performed with GraphPad Prism 6.0 software (GraphPad Prism, Inc., San Diego, USA). The values shown represent the mean \pm SEM for each experimental group. Evaluation of normality data distribution was performed using the Shapiro-Wilk test. Assessment of the statistical significance of differences between mean values was performed by one-way 
ANOVA and the Newman-Keuls' test. A $p<0.05$ was considered significant. Analysis of association between different variables was carried-out using the Pearson correlation coefficient.

\section{Results}

General physiological parameters (A), food intake (B), serum parameters (C), insulin resistance parameters (D), and liver parameters (E) of CD and HFD fed mice receiving $\mathrm{HT}$ supplementation (Table 1 )

HFD produced a significant increment of body weight of animals at the end of the intervention, but HT supplementation did not produce weight modification either in control or in HFD mice. Liver weight was also not modified by HFD nor by HT. However, a significant difference was observed for the ratio liver weight/final body weight. Food intake was similar for both experimental groups, energy intake of HFD group being significantly higher than CD. Supplementation with HT did not generate significant changes in dietary intake. Serum parameters were all modified by HFD compared to control. HT supplementation did not modify these parameters in controls, but significantly reduced triacylglycerol, total cholesterol and LDL-cholesterol in HFD mice, without changes in HDL-cholesterol. Insulin resistance parameters were also drastically modified by HFD, with significant increases in fasting glucose, fasting insulin, and HOMA values. HT supplementation reduced these parameters but not to the levels of the respective controls. Serum AST and ALT transaminases were not modified by the HFD nor HT supplementation. These results demonstrate that HT improved some serum parameters and markers of insulin resistance, without restoration to the levels observed in control animals. Figure 1 shows study of liver morphology indicated the presence of severe micro and macrovesicular steatosis in the HFD group (Fig. 1c), compared to those subjected to CD and CD + HT (Fig. 1a and b), whereas hepatic fat accumulation was recorded as mild in the HFD + HT group (Fig. 1d). Respect to liver score steatosis, this parameter was increased by HFD in mice (Fig. 1e), and attenuated by HT but not to the same values in control groups (Fig. 1e).

Table 1 General and biochemical parameters in control mice and high-fat diet fed mice subjected to hydroxytyrosol (HT) supplementation

\begin{tabular}{|c|c|c|c|c|}
\hline & \multicolumn{4}{|l|}{ Groups } \\
\hline & \multicolumn{2}{|c|}{ Control diet (CD) } & \multicolumn{2}{|c|}{ High-fat diet (HFD) } \\
\hline & Saline (a) & $\mathrm{HT}(\mathrm{b})$ & Saline (c) & $\mathrm{HT}(\mathrm{d})$ \\
\hline \multicolumn{5}{|l|}{ A. General parameters } \\
\hline Initial body weight (g) & $13.5 \pm 0.6$ & $14.0 \pm 0.7$ & $14.0 \pm 0.5$ & $13.2 \pm 0.8$ \\
\hline Final body weight (g) & $34.4 \pm 2.7^{c, d}$ & $36.2 \pm 3.1^{c, d}$ & $46.8 \pm 4.5^{\mathrm{a}, \mathrm{b}}$ & $42.5 \pm 3.2^{a, b}$ \\
\hline Liver weight (g) & $1.19 \pm 0.2$ & $1.21 \pm 0.4$ & $1.25 \pm 0.3$ & $1.24 \pm 0.4$ \\
\hline Liver weight (g)/ final body weight (g) ratio & $0.034 \pm 0.01^{c, d}$ & $0.033 \pm 0.01^{c, d}$ & $0.026 \pm 0.005^{a, b, d}$ & $0.029 \pm 0.01^{a, b, c}$ \\
\hline \multicolumn{5}{|l|}{ B. Food and Energy intake } \\
\hline Food intake (g/day) & $2.4 \pm 0.5$ & $2.3 \pm 0.4$ & $2.7 \pm 0.6$ & $2.6 \pm 0.3$ \\
\hline Energy intake (kcal/day) & $9.22 \pm 0.8^{c, d}$ & $8.84 \pm 0.7^{c, d}$ & $14.2 \pm 1.4^{\mathrm{a}, \mathrm{b}}$ & $13.6 \pm 1.3^{\mathrm{a}, \mathrm{b}}$ \\
\hline \multicolumn{5}{|l|}{ C. Lipid parameters } \\
\hline Triacylglycerols (mg/dL) & $130.5 \pm 7.2^{c, d}$ & $120.6 \pm 6.5^{c, d}$ & $180.6 \pm 11.5^{\mathrm{a}, \mathrm{b}, \mathrm{d}}$ & $156.3 \pm 8.4^{\mathrm{a}, \mathrm{b}, \mathrm{c}}$ \\
\hline Total cholesterol (mg/dL) & $73.5 \pm 8.5^{\mathrm{c,d}}$ & $68.7 \pm 6.9^{c, d}$ & $126.5 \pm 15.3^{\mathrm{a}, \mathrm{b}, \mathrm{d}}$ & $103.6 \pm 9.6^{\mathrm{a}, \mathrm{b}, \mathrm{c}}$ \\
\hline LDL-cholesterol (mg/dL) & $44.3 \pm 3.8^{c, d}$ & $40.2 \pm 3.3^{c, d}$ & $78.6 \pm 6.5^{\mathrm{a}, \mathrm{b}, \mathrm{d}}$ & $63.5 \pm 5.4^{\mathrm{a}, \mathrm{b}, \mathrm{c}}$ \\
\hline HDL-cholesterol (mg/dL) & $26.9 \pm 3.4^{c, d}$ & $24.7 \pm 2.9^{c, d}$ & $44.9 \pm 4.8^{\mathrm{a}, \mathrm{b}}$ & $36.3 \pm 5.7^{a, b}$ \\
\hline \multicolumn{5}{|l|}{ D. Insulin resistance } \\
\hline Fasting glucose (mg/dL) & $123.5 \pm 5.6^{c, d}$ & $119.4 \pm 4.9^{c, d}$ & $235.5 \pm 29.4^{a, b, d}$ & $184.6 \pm 16.5^{\mathrm{a}, \mathrm{b}, \mathrm{c}}$ \\
\hline Fasting insulin (units/mL) & $5.47 \pm 0.7^{c, d}$ & $5.19 \pm 0.8^{c, d}$ & $18.4 \pm 1.7^{a, b, d}$ & $12.2 \pm 1.1^{a, b, c}$ \\
\hline HOMA & $1.25 \pm 0.3^{c . d}$ & $1.17 \pm 0.2^{c, d}$ & $8.92 \pm 1.0^{\mathrm{a}, \mathrm{b}, \mathrm{d}}$ & $6.45 \pm 0.6^{a, b, d}$ \\
\hline \multicolumn{5}{|l|}{ E. Serum transaminases } \\
\hline AST (U/L) & $139.3 \pm 17.8$ & $142.7 \pm 20.3$ & $171.5 \pm 28.5$ & $148.6 \pm 23$ \\
\hline $\mathrm{ALT}(\mathrm{U} / \mathrm{L})$ & $78.6 \pm 9.8$ & $65.2 \pm 6.4$ & $80.2 \pm 10.7$ & $75.3 \pm 5.6$ \\
\hline
\end{tabular}

Values represent means \pm SEM for 12-14 mice per experimental group. Significant differences between the groups are indicated by the letter identifying each group (one-way ANOVA and Newman-Keuls' post-test; $p<0.05$ ) 

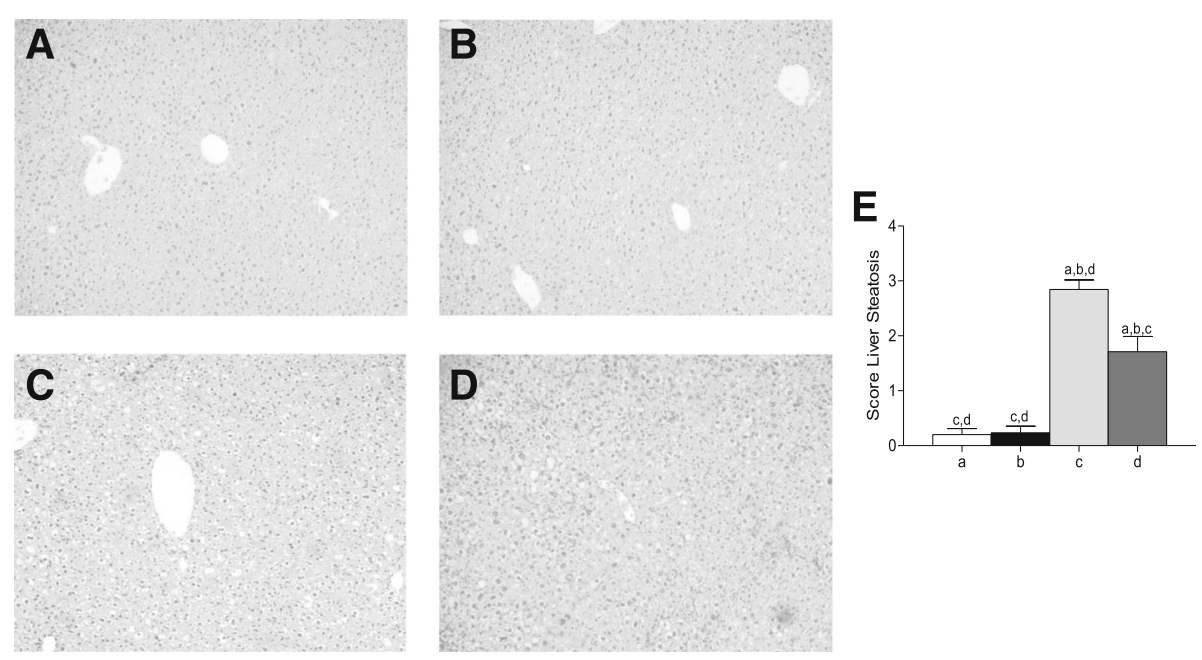

$100 \mu \mathrm{m}$

Fig. 1 Liver histology in control and high-fat diet (HFD) fed mice receiving hydroxytyrosol (HT) supplementation. Representative liver sections are from $\mathbf{a} \mathrm{CD}$ diet, $\mathbf{b} \mathrm{CD}+\mathrm{HT}$, $\mathbf{c} H F D$, $\mathbf{d} H F D+H T$ (haematoxylin-eosin liver sections from of 8-10 animals per experimental group; original magnification $\times 10$ ) and (e) Score Liver Steatosis. Significant differences between the groups are indicated by the letter identifying each group (one-way ANOVA and Newman-Keuls' post-test; $p<0.05$ )

HT supplementation normalizes the changes induced by HFD on liver desaturase activities and desaturase gene expression, SREBP-1c mRNA expression, and SREBP 1-c DNA binding activity

Figure 2 shows $\Delta-5$ desaturase (Fig. 2a) and $\Delta-6$ desaturase (Fig. 2b) activities, $\Delta-6$ desaturase (Fig. 2c) and $\Delta-5$ desaturase (Fig. 2d) mRNA expression, SREBP 1c mRNA expression (Fig. 2e) and SREBP 1-c DNA binding activity (Fig. 2f), after HFD and HT supplementation. The activity of both desaturases was strongly reduced by HFD, but recovery to control values was achieved by HT. In contrast, HFD produced a significantly increase of mRNA expression of both desaturases, which returned to control values by HT, a paradoxical effect can be interpreted as a compensatory response to the reduction in the activity of desaturases. SREBP 1-c mRNA expression and SREBP 1-c DNA binding activity were also increased by HFD and reduced by HT, without reaching the control figures. Again, the increased mRNA and DNA binding activity of SREBP 1 -c by HFD may be a compensatory mechanism to the reduction in the activity of desaturases. Results show a strong metabolic effect of HFD on parameters related to lipid metabolism and a relevant recovery response after HT supplementation.

HT supplementation offsets the changes in oxidative stress-related parameters induced by HFD in plasma and liver

Figure 3 shows oxidative stress-related parameters obtained from mice fed control diet + saline $(C D+\mathrm{sa}-$ line), control diet $+\mathrm{HT}(\mathrm{CD}+\mathrm{HT}), \mathrm{HFD}+$ saline, and HFD + HT, namely, plasma TBARs (Fig. 3a), plasma antioxidant capacity (Fig. 3b), liver GSH (Fig. 3c), liver GSSG (Fig. 3d), total GSH equivalents (Fig. 3e), liver GSH/GSSG ratio (Fig. 3f), and liver TBARs (Fig. 3g). Results demonstrate that HFD significantly increased plasma TBARs concomitant with a reduction of plasma antioxidant capacity. HT improved these values reducing TBARs to values close, but not similar, to control values. HT also increased plasma antioxidant capacity, restoring the values found in controls. Liver GSH but not GSSG was reduced by HFD, however, HT restored GSH, total GSH equivalent, and GSH/GSSG ratio to values similar to control. Liver TBARs were also increased by HFD and restored by $\mathrm{HT}$ but not to the same values in controls. Results demonstrate an effective protection of HT supplementation against modification of plasma and liver oxidative stress-related parameters induced by HFD.

In addition, Fig. 3 shows the activity of liver SOD (Fig. 3h), CAT (Fig. 3i), PGX (Fig. 3j), and GR (Fig. 3k) after HFD and HT supplementation. The activity of all these enzymes was significantly reduced by HFD. However, HT supplementation restored these activities to values similar to those found in controls. Results demonstrate a major improvement of the antioxidant enzyme potential of the liver by HT supplementation after HFD feeding.

\section{Correlations between liver $\Delta-5$ and $\Delta-6$ desaturase activities with oxidative stress-related parameters}

Figure 4 shows the correlation between liver desaturase activities $(\Delta-5$ and $\Delta-6)$ with oxidative stress parameters. A positive correlation is observed for liver GSH content 

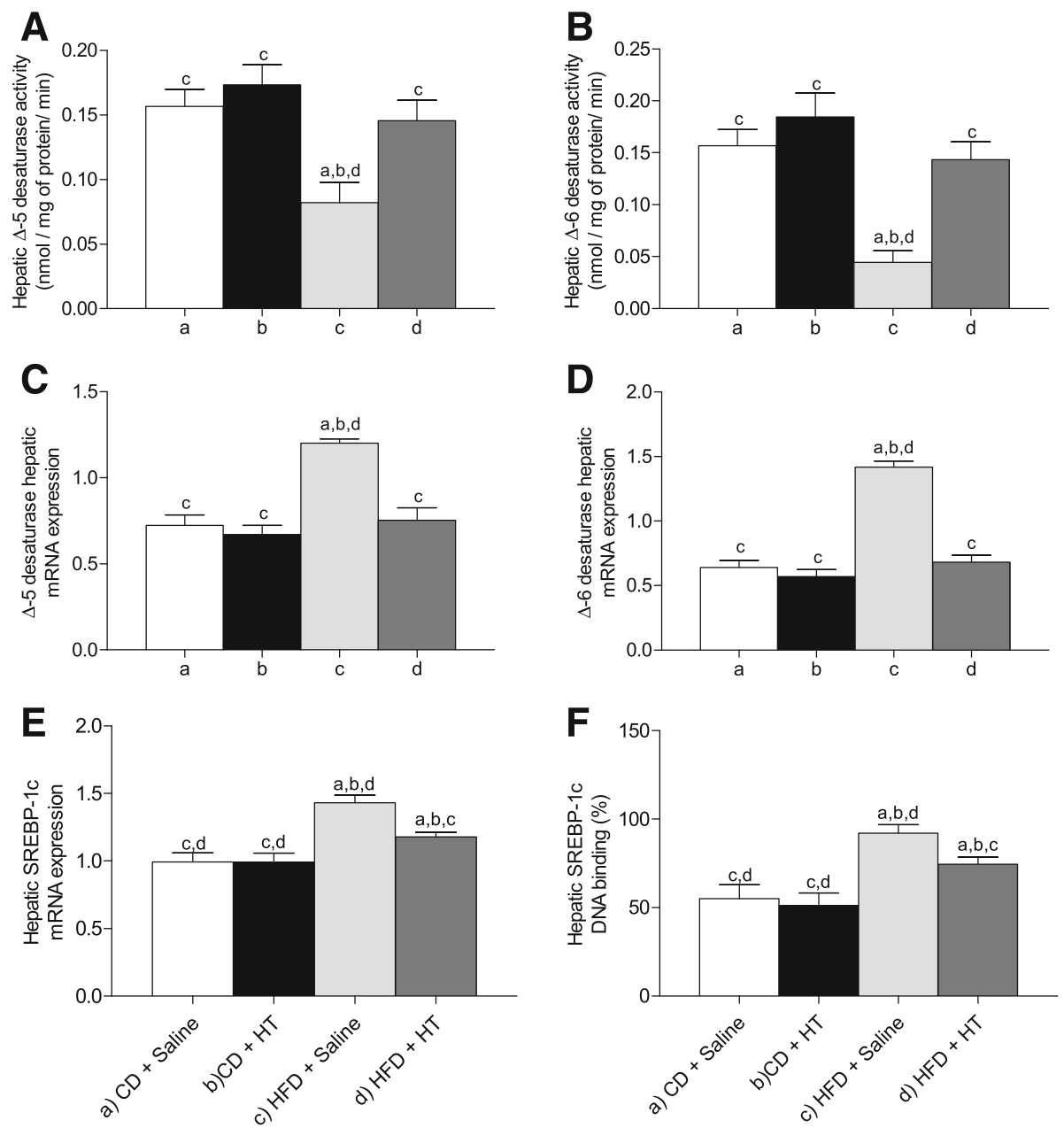

Fig. 2 Liver desaturase activities and expression and liver SREBP-1c expression and DNA-binding activity from control mice and high fat diet (HFD) fed mice receiving hydroxytyrosol (HT) supplementation. a $\Delta-5$ desaturase activity; $\mathbf{b}, \Delta-6$ desaturase activity; $\mathbf{c}, \Delta-5$ desaturase mRNA expression; $\mathbf{d}, \Delta-6$ desaturase mRNA expression; e, SREBP-1c mRNA expression; and f $\mathbf{f}$, SREBP-1c DNA binding activity. Values represent means \pm SEM for 12-14 mice per experimental group. Significant differences between the groups are indicated by the letter identifying each group (one-way ANOVA and Newman-Keuls' post-test; $p<0.05$ )

and $\Delta-5$ desaturase activity (Fig. 4a; $r=0.85, p<0.0001$ ) and $\Delta-6$ desaturase activity (Fig. $4 \mathrm{~b} ; r=0.88, p<0.0001$ ), as well as for hepatic GSH/GSSG ratios and $\Delta-5$ desaturase activity (Fig. 4c; $r=0.84, p<0.0001$ ) and $\Delta-6$ desaturase activity (Fig. $4 \mathrm{~d} ; r=0.89, p<0.0001$ ). Liver TBARs content exhibited a negative correlation with $\Delta-5$ desaturase activity (Fig. 4e; $r=-0.88, p<0.0001$ ) and with $\Delta-6$ desaturase activity (Fig. 4f; $r=-0.91, p<0.0001$ ). These associations indicate that the desaturase activity of the liver is privileged when an elevated anti-oxidative status is present, either through higher GSH levels and GSH/GSSG ratios or lower TBARs contents, suggesting that oxidative stress may affect n-6 and n-3 LCPUFA biosynthesis from the respective precursors. Also, to evaluate the correlation between plasma antioxidant capacity with the activity of liver desaturase enzyme $(\Delta-5$ and $\Delta-6$ was observed a positive correlation into this parameter of redox systemic status with the activity of this enzymes $(\Delta-5 ; r=0.88, p<0.0001$ and $\Delta-6 ; r=0.91$, $p<0.0001$, respectively).

HT supplementation counteracts the changes in the fatty acid composition of phospholipids from liver, erythrocyte, brain, heart, and testicle induced by HFD

Table 2 shows that, with the exception of LA, most FAs were reduced by the HFD compared to control. HT supplementation did not produce differences in control animals, but FAs such as ALA, AA, EPA, and DHA were significantly increased in HFD group receiving $\mathrm{HT}$ to the levels observed in control animals. In HFD animals 


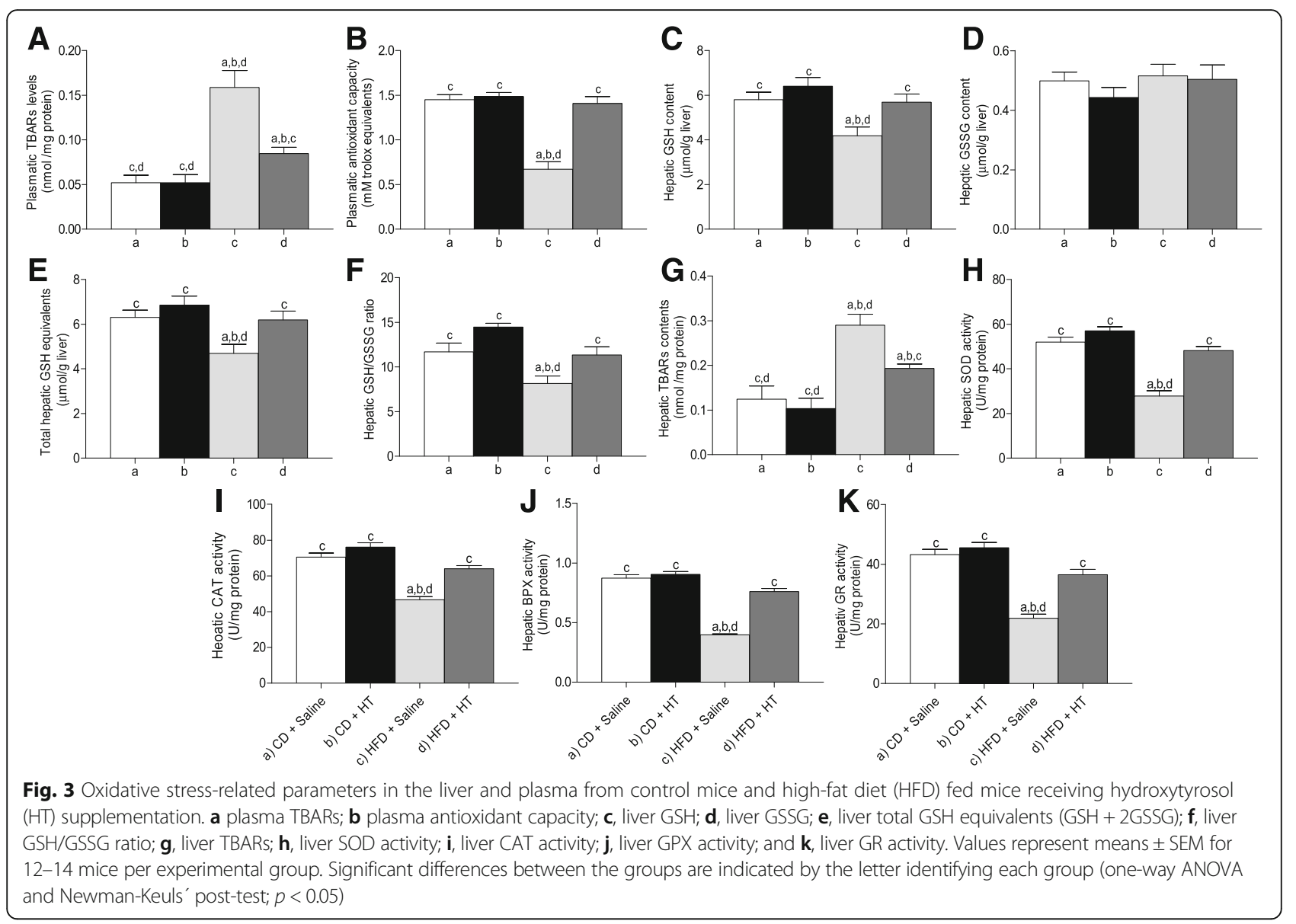

supplemented with HT, total SFAs were reduced whereas total PUFAs, total LCPUFAs, total n-6 LCPUFAs, and total n-3 LCPUFAs were increased to levels similar to those found in controls (saline or HT). N-6/n3 LCPUFA ratio was restored to the value found in controls (saline or HT) when HT was incorporated to the HFD. Data show that supplementation with HT avoids the reduction of n- 6 and n-3 PUFA and of n-6 and n-3 LCPUFA induced by the HFD in mice, reflecting a protective action of the polyphenol on the FA composition of liver phospholipids.

In contrast to that observed in liver tissue, erythrocyte phospholipids showed LA, ALA, and AA levels that were not modified by HFD and no effect of HT was observed, however, the main n-3 LCPUFAs EPA and DHA were significantly reduced by HFD, but restored to the control level by HT (Table 3). A similar effect was observed for other minor n-6 and n-3 LCPUFAs such as DPA (n-6) and DPA $(n-3)$. As a result of the HT-induced recovery of EPA and DHA, total LCPUFAs, total n-3 LCPUFAs, and n-6/n-3 LCPUFA ratios reached values similar to those found in control (Table 3). HT supplementation did not modify the FA level of control mice (saline or HT; Table 3).
FA composition of brain phospholipids was strongly modified by HFD, showing a notably response to HT supplementation (Table 4). HFD increased C16:0 and DPA (n-6), but reduced ALA, AA, EPA, DPA (n-3), and DHA; although HT supplementation in HFD fed mice restored these FA to values similar to control (saline and HT). The same result is observed for total PUFAs, total LCPUFAs, total n-6 LCPUFAs, total n-3 LCPUFAs and n-6/n-3 LCPUFA ratios (Table 4). These results demonstrate that brain is a very sensitive tissue to the modification of FA supply and that HT may exert an important protection against modification of FA profiles caused by a HFD.

The FA composition of heart phospholipids was also modified by the dietary intervention with HT (Table 5). The increase of SFA such as C16:0, and total SFA produced by HFD, was normalized to values similar to control by HT supplementation. Besides, the reduction of ALA, EPA, DPA (n-6), DPA (n-3), and DHA produced by HFD was also normalized by HT to values close to the control (both saline and HT). Although total n-6 LCPUFA levels were not recovered by HT as observed in other tissues, total n-3 LCPUFAs showed an 

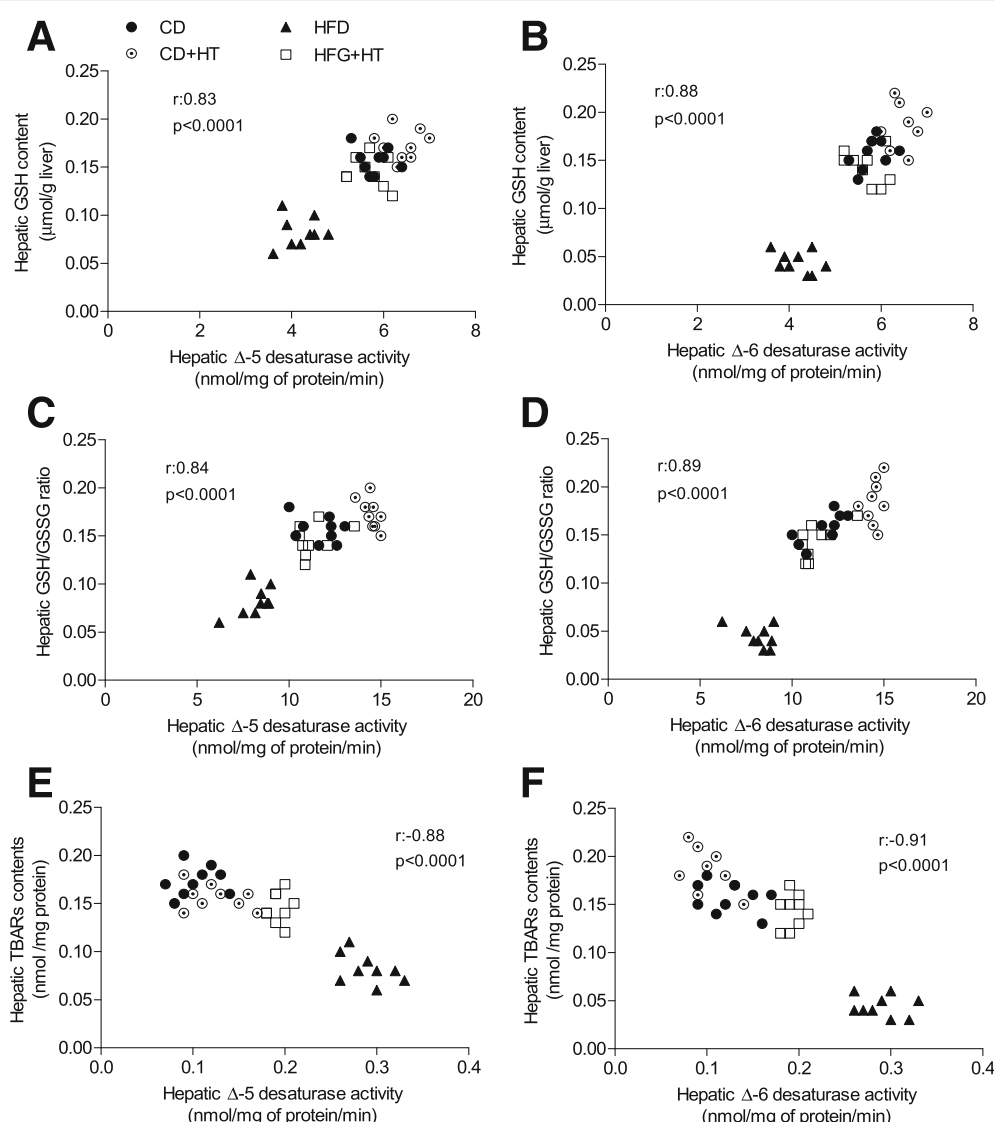

Fig. 4 Correlation of $\Delta-5$ and $\Delta-6$ desaturase activities with oxidative stress-related parameters in the liver of control mice and high-fat diet (HFD) fed mice receiving hydroxytyrosol (HT) supplementation. a GSH content v/s $\Delta-5$ desaturase activity; $\mathbf{b}$, GSH content v/s $\Delta-6$ desaturase activity; c , GSH/GSSG ratio $\mathrm{v} / \mathrm{s} \Delta-5$ desaturase activity; $\mathbf{d}$, GSH/GSSG ratio $\mathrm{v} / \mathrm{s} \Delta-6$ desaturase activity; e, TBARs content v/s $\Delta-5$ desaturase activity; and f, TBARs content v/s $\Delta-6$ desaturase activity

increase without reaching the values observed in controls. HFD-induced reduction in the n-6/n-3 LCPUFA ratio exhibited a partial recovered by HT (Table 5 ). Results demonstrate that FA profile of the heart, which is a highly demanding metabolic tissue, is also modified by HFD and positively affected by HT availability.

The FA composition of testicle phospholipids was modified by HFD and HT interventions (Table 6), as observed in the other studied tissues. HT supplementation had no effect in the control groups, but it restored the values of ALA, EPA, DPA (n-6), DPA (n-3), and DHA, which were significantly reduced by the HFD, to figures close to the control values. HFD increased total SFA and n-6/n-3 LCPUFA ratio and decreased total LCPUFAs and total n-3 LCPUFAs, values that were also restored to control levels by HT supplementation.

\section{Discussion}

The liver has a central role in the synthesis of $n-6$ and n-3 LCPUFAs, this tissue being responsible for the majority of this conversion through the processes of desaturation and elongation of AL and ALA to the respective metabolic products [34]. The role of $\Delta-5$ and $\Delta-6$ desaturases in this process is highly regulated by hormones, particularly by insulin-mediated upregulation of the gene expression of the enzymes [1, 10, 15]. However, several conditions can significantly diminish the capacity of the liver for LCPUFA synthesis from their precursors thus affecting the hepatic levels of n-6 n-3 LCPUFAs, including (i) the lack of nutrients such as zinc [35]; (ii) the excessive ethanol consumption [36]; and (iii) the existence of certain polymorphisms in the gene sequences of $\Delta-5$ and $\Delta-6$ desaturases that reduces the activity of these enzymes [37]. An interesting situation related to the activity of $\Delta-5$ and $\Delta-6$ desaturases is liver steatosis, a pathological condition in which the oxidative stress of nutritional origin generated by fat overload (lipotoxicity) also results in a reduction in the desaturation capacity of the tissue with low levels of n-6 and n-3 LCPUFAs [14, 38, 39], effects that are also 
Table 2 Fatty acid composition of liver phospholipids from control mice and high-fat diet fed mice subjected to hydroxytyrosol (HT) supplementation

\begin{tabular}{|c|c|c|c|c|}
\hline \multirow[b]{5}{*}{ Fatty acid } & \multicolumn{4}{|c|}{ Fatty acid composition (g/100 g FAME) } \\
\hline & \multicolumn{4}{|l|}{ Groups } \\
\hline & \multicolumn{2}{|c|}{ Control diet (CD) } & \multicolumn{2}{|c|}{ High fat diet (HFD) } \\
\hline & Saline & HT & Saline & HT \\
\hline & (a) & (b) & (c) & (d) \\
\hline$\overline{C 16: 0}$ & $31.2 \pm 2.6^{c}$ & $28.9 \pm 2.1^{c}$ & $43.6 \pm 4.2^{a, b, d}$ & $32.4 \pm 3.3^{c}$ \\
\hline C18:0 & $4.31 \pm 0.6^{b}$ & $3.15 \pm 0.2^{a}$ & $4.62 \pm 0.6^{b}$ & $4.40 \pm 0.4^{b}$ \\
\hline C18:1n-9 & $23.4 \pm 1.8$ & $25.6 \pm 2.3$ & $22.2 \pm 1.6$ & $24.8 \pm 2.0$ \\
\hline C18:2n-6 (LA) & $13.3 \pm 1.1$ & $14.5 \pm 1.3$ & $11.8 \pm 1.0$ & $12.1 \pm 1.2$ \\
\hline C18:3n-6 & $1.10 \pm 0.1$ & $0.97 \pm 0.1$ & $0.95 \pm 0.05$ & $0.99 \pm 0.05$ \\
\hline C18:3n-3 (ALA) & $1.19 \pm 0.1^{c}$ & $1.23 \pm 0.2^{c}$ & $0.89 \pm 0.05^{\mathrm{a}, \mathrm{b}, \mathrm{d}}$ & $1.09 \pm 0.04^{c}$ \\
\hline C18:4n-3 & $0.25 \pm 0.03^{c}$ & $0.27 \pm 0.05^{c}$ & $0.09 \pm 0.02^{\mathrm{a}, \mathrm{b}, \mathrm{d}}$ & $0.23 \pm 0.04^{c}$ \\
\hline$C 20: 3 n-6$ & $0.27 \pm 0.05^{c}$ & $0.29 \pm 0.04^{c}$ & $0.15 \pm 0.03^{\mathrm{a}, \mathrm{b}, \mathrm{d}}$ & $0.26 \pm 0.05^{c}$ \\
\hline C20:4n-6 (AA) & $10.2 \pm 0.9^{c}$ & $11.5 \pm 0.7^{c}$ & $5.95 \pm 0.4^{a, b, d}$ & $10.4 \pm 0.8^{c}$ \\
\hline$C 20: 4 n-3$ & $0.16 \pm 0.04^{c}$ & $0.17 \pm 0.05^{c}$ & $0.04 \pm 0.02^{a, b, d}$ & $0.14 \pm 0.3^{c}$ \\
\hline C20:5n-3 (EPA) & $1.07 \pm 0.1^{c}$ & $1.10 \pm 0.1^{c}$ & $0.32 \pm 0.04^{a, b, d}$ & $1.05 \pm 0.05^{c}$ \\
\hline C22:5n-6 (DPAn-6) & $0.08 \pm 0.01^{c}$ & $0.09 \pm 0.02^{c}$ & $0.03 \pm 0.01^{a, b, d}$ & $0.08 \pm 0.01^{c}$ \\
\hline C22:5n-3 (DPAn-3) & $0.09 \pm 0.02^{c}$ & $0.08 \pm 0.01^{c}$ & $0.04 \pm 0.01^{\mathrm{a}, \mathrm{b}, \mathrm{d}}$ & $0.08 \pm 0.01^{c}$ \\
\hline $\mathrm{C} 22: 6 \mathrm{n}-3(\mathrm{DHA})$ & $4.21 \pm 0.2^{c}$ & $4.39 \pm 0.3^{c}$ & $1.95 \pm 0.1^{a, b, d}$ & $4.12 \pm 0.2^{c}$ \\
\hline Total SFAs & $37.5 \pm 3.1^{c}$ & $36.4 \pm 2.9^{c}$ & $48.9 \pm 4.4^{\mathrm{a}, \mathrm{b}, \mathrm{d}}$ & $38.7 \pm 3.5^{c}$ \\
\hline Total MUFAs & $26.6 \pm 2.2$ & $28.5 \pm 1.9$ & $24.4 \pm 2.4$ & $26.7 \pm 2.0$ \\
\hline Total PUFAs & $35.9 \pm 3.1^{c}$ & $35.1 \pm 3.6^{c}$ & $26.7 \pm 2.3^{\mathrm{a}, \mathrm{b}, \mathrm{d}}$ & $34.6 \pm 3.3^{c}$ \\
\hline Total LCPUFAs & $16.6 \pm 1.5^{c}$ & $17.9 \pm 1.1^{c}$ & $8.62 \pm 0.5^{a, b, d}$ & $16.4 \pm 0.9^{c}$ \\
\hline Total n-6 LCPUFAs & $11.0 \pm 0.7^{c}$ & $12.1 \pm 0.8^{c}$ & $6.17 \pm 0.3^{a, b, d}$ & $10.9 \pm 0.8^{c}$ \\
\hline Total n-3 LCPUFAs & $5.60 \pm 0.3^{c}$ & $5.80 \pm 0.4^{c}$ & $2.45 \pm 0.2^{a, b, d}$ & $5.50 \pm 0.5^{c}$ \\
\hline$n-6 / n-3$ LCPUFA ratio & $1.96 \pm 0.1^{c}$ & $2.08 \pm 0.05^{c}$ & $2.51 \pm 0.2^{\mathrm{a}, \mathrm{b}, \mathrm{d}}$ & $1.98 \pm 0.1^{c}$ \\
\hline
\end{tabular}

Values are expressed as $\mathrm{g}$ fatty acid per $100 \mathrm{~g}$ FAME and represent the mean \pm SEM for $n=12-14$ mice per experimental group. Significant differences between the groups are indicated by the letter identifying each group (one-way ANOVA and the Newman-Keuls' post-test; $p<0.05$ ). Saturated fatty acids (SFAs) correspond to C12:0, C14:0, C16:0 and C18:0. Monounsaturated fatty acids (MUFAs) correspond to C14:1n-7, C16:1n-7 and C18:1n-9. Polyunsaturated fatty acids (PUFAs) correspond to C18:2n-6, C18:3n-3, C20:4n-6, C20:5n-3, C22:5n-3, and C22:6n-3; n-6 LCPUFAs are C20:4n-6 and C22:5n-3; n-3 LCPUFAs are C20:5n-3, C22:5n-3, and C22:6n-3; n-6/n-3 LCPUFA ratio: C20:4n-6/ (C20:5n-3 + C22:5n-3 + C22:6n-3)

observed after a HFD [15, 40]. Also, in overfeeding conditions the increment in gene expression of $\Delta-5$ and $\Delta-6$ desaturase enzymes is not sufficient to compensate the reduction of $n-6$ and $n-3$ LCPUFAs [39].

Data presented show that HFD induced significant metabolic changes in mice including (i) insulin resistance, evidenced by the enhancement in the HOMA index, concomitantly with increases in serum triacylglycerol's and cholesterol levels; (ii) a rise in plasma and liver oxidative stress status involving a diminution in the activity of antioxidant enzymes and derangement in the GSH system; and (iii) a significant reduction in the synthesis and storage of $n-6$ and n-3 LCPUFAs in the studied tissues. The substantial diminution in the hepatic levels of LCPUFAs by HFD, particularly those from the $n-3$ series (EPA, DHA and DPA), may be ascribed to the drastic reduction of the liver activity of desaturase enzymes achieved, considering their relevance in LCPUFA metabolism [15, 40]. This effect can be contributed by the diminution in the hepatic levels of the n-3 LCPUFA precursor ALA observed (Table 2) and by the enhancement in the oxidative stress status of the liver (Fig. 3) that can elicit desaturase inactivation. The latter suggestion is based on the finding that oxidative stress triggers the carbonylation and misfolding of proteins, thus inducing endoplasmic reticulum (ER) stress $[41,42]$. ER stress is a response that can be caused by the excess of palmitic acid (C16:0) induced by the HFD (Table 2), a major metabolite responsible for generating pro-oxidant status and lipotoxicity in the liver directly promoting protein folding [43]. The association of liver desaturation capacity and oxidative stress is supported by the significant direct correlation found between desaturase activity and the glutathione status and the inverse relationship concerning desaturase activity and the lipid 
Table 3 Fatty acid composition of erythrocyte phospholipids from control mice and high-fat diet (HFD) fed mice receiving hydroxytyrosol (HT) supplementation

\begin{tabular}{|c|c|c|c|c|}
\hline \multirow[b]{5}{*}{ Fatty acid } & \multicolumn{4}{|c|}{ Fatty acid composition (g/100 g FAME) } \\
\hline & \multicolumn{4}{|l|}{ Groups } \\
\hline & \multicolumn{2}{|c|}{ Control diet (CD) } & \multicolumn{2}{|c|}{ High fat diet (HFD) } \\
\hline & Saline & HT & Saline & HT \\
\hline & (a) & (b) & (c) & (d) \\
\hline $\mathrm{C} 16: 0$ & $34.5 \pm 3.1^{c}$ & $31.9 \pm 2.9^{c}$ & $41.6 \pm 3.8^{\mathrm{a}, \mathrm{b}, \mathrm{d}}$ & $36.6 \pm 3.5^{c}$ \\
\hline C18:0 & $3.62 \pm 0.3^{c, d}$ & $3.45 \pm 0.4^{c, d}$ & $6.58 \pm 0.7^{\mathrm{a}, \mathrm{b}}$ & $5.58 \pm 0.6^{a, b}$ \\
\hline C18:1n-9 & $24.6 \pm 1.9$ & $25.6 \pm 2.2$ & $22.9 \pm 2.3$ & $24.8 \pm 2.5$ \\
\hline C18:2n-6 (LA) & $9.91 \pm 1.2$ & $10.2 \pm 0.9$ & $8.66 \pm 1.7$ & $9.52 \pm 1.5$ \\
\hline C18:3n-3 (ALA) & $1.21 \pm 0.5$ & $1.12 \pm 0.3$ & $1.05 \pm 0.3$ & $1.05 \pm 0.3$ \\
\hline$C 20: 4 n-6(A A)$ & $14.6 \pm 1.4$ & $15.7 \pm 1.6$ & $12.6 \pm 1.1$ & $12.4 \pm 1.3$ \\
\hline$C 20: 5 n-3(E P A)$ & $2.05 \pm 0.3^{c}$ & $2.19 \pm 0.4^{c}$ & $0.75 \pm 0.03^{a, b, d}$ & $1.96 \pm 0.2^{c}$ \\
\hline C22:5n-6 (DPAn-6) & $0.16 \pm 0.04^{c}$ & $0.19 \pm 0.05^{c}$ & $0.05 \pm 0.01^{\mathrm{a}, \mathrm{b}, \mathrm{d}}$ & $0.12 \pm 0.02^{c}$ \\
\hline C22:5n-3 (DPAn-3) & $0.78 \pm 0.05^{c}$ & $0.86 \pm 0.06^{c, d}$ & $0.25 \pm 0.01^{a, b, d}$ & $0.70 \pm 0.04^{b, c}$ \\
\hline C22:6n-3 (DHA) & $4.11 \pm 0.3^{c}$ & $4.32 \pm 0.4^{c}$ & $1.98 \pm 0.1^{\mathrm{a}, \mathrm{b}, \mathrm{d}}$ & $3.98 \pm 0.3^{c}$ \\
\hline Total SFAs & $38.8 \pm 2.9^{c}$ & $36.5 \pm 2.6^{c, d}$ & $49.7 \pm 4.4^{a, b}$ & $43.5 \pm 3.9^{b}$ \\
\hline Total MUFAs & $26.4 \pm 2.5$ & $27.9 \pm 2.4$ & $24.5 \pm 2.2$ & $24.8 \pm 2.7$ \\
\hline Total PUFAs & $34.8 \pm 3.3^{c}$ & $35.6 \pm 3.6^{c}$ & $25.8 \pm 2.2^{a, b}$ & $31.7 \pm 2.6$ \\
\hline Total LCPUFAs & $22.9 \pm 1.7^{c}$ & $23.7 \pm 2.1^{c}$ & $15.8 \pm 1.1^{\mathrm{a}, \mathrm{b}, \mathrm{d}}$ & $20.2 \pm 1.5^{c}$ \\
\hline Total n-6 LCPUFAs & $14.9 \pm 1.4$ & $16.0 \pm 1.6^{c}$ & $12.7 \pm 0.9^{b}$ & $12.7 \pm 1.4$ \\
\hline Total n-3 LCPUFAs & $8.00 \pm 0.7^{c}$ & $7.70 \pm 0.5^{c}$ & $3.10 \pm 0.2^{a, b, d}$ & $7.50 \pm 0.6^{c}$ \\
\hline n-6/n-3 LCPUFA ratio & $1.86 \pm 0.2^{c}$ & $2.07 \pm 0.3^{c}$ & $4.10 \pm 0.4^{a, b, d}$ & $1.69 \pm 0.3^{c}$ \\
\hline
\end{tabular}

peroxidation potential (Fig. 4). Despite the HFD-induced downregulation of $\Delta-5$ and $\Delta-6$ desaturase activity, the mRNA expression of both desaturases was upregulated, a finding that agrees with the enhancement in the mRNA expression of SREBP-1c and its DNA binding capacity, a lipogenic transcription factor mediating the transcriptional activation of desaturase genes by insulin and inhibition by LCPUFAs [20, 44]. Although upregulation of SREBP-1c by insulin is unlikely to occur under insulin resistance conditions, SREBP-1c induction by HFD could be accomplished by ER-stress, which, in addition, upregulates the expression of other lipogenic factors including $\mathrm{C} / \mathrm{EBP}$ and peroxisome proliferatoractivated receptor- $\gamma$ (PPAR- $\gamma$ ) [45]. Furthermore, genetic ablation of solute carrier family 7a3a mediating arginine transport for nitric oxide (NO) biosynthesis also leads to hepatic steatosis in liver cells from zebrafish, mice, and humans, through downregulation of NO-dependent AMPK-PPAR- $\alpha$ signaling [46]. However, additional studies are required to assess the involvement of Slc7a3a in HFD-induced liver steatosis.

A direct consequence of HFD-induced decrease in the desaturase activity of the liver, with reduction in the synthesis of LCPUFAs, is the diminution of the n-6 and n-3 LCPUFA levels in red blood cells, brain, heart, and testicle, considering that the liver is the main organ for LCPUFA biosynthesis in mammals [9, 10]. In this context, it is important to note that the LCPUFA content in erythrocytes is considered a metabolic marker of the liver synthesis of n-6 and n3 LCPUFAs from their respective precursors [10, 14, $15,38,47]$. Moreover, reduction in the hepatic synthesis and transport of LCPUFAs to extrahepatic tissues may have a direct impact upon brain structure and function [48], in the appropriate functioning of heart cell membranes, representing a main mechanism supporting the cardio-protective properties of $n-3$ LCPUFA [49], and in sperm viability, considering that DHA is mainly accumulated into sperms having a relevant role in fertilization [50-52]. For example when the contribution of dietary LCPUFA is low, the synthesis of these fatty acids starting from their 18 carbon atoms precursors is increased in a significant form [53]. In this regard, when the diet not supply DHA, the synthesis of this fatty acid in the brain starting from its precursor increases up to 100 times [54]. 
Table 4 Fatty acid composition of brain phospholipids from control mice and high-fat diet (HFD) fed mice receiving hydroxytyrosol (HT) supplementation

\begin{tabular}{|c|c|c|c|c|}
\hline \multirow[b]{5}{*}{ Fatty acid } & \multicolumn{4}{|c|}{ Fatty acid composition (g/100 g FAME) } \\
\hline & \multicolumn{4}{|l|}{ Groups } \\
\hline & \multicolumn{2}{|c|}{ Control diet (CD) } & \multicolumn{2}{|c|}{ High fat diet (HFD) } \\
\hline & Saline & HT & Saline & HT \\
\hline & (a) & (b) & (c) & (d) \\
\hline $\mathrm{C} 16: 0$ & $35.6 \pm 3.1^{c}$ & $34.3 \pm 3.3^{c}$ & $47.4 \pm 4.6^{\mathrm{a}, \mathrm{b}, \mathrm{d}}$ & $37.3 \pm 3.6^{c}$ \\
\hline C18:0 & $5.95 \pm 0.6$ & $5.58 \pm 0.4$ & $5.15 \pm 0.4$ & $5.75 \pm 05$ \\
\hline C18:1n-9 & $19.8 \pm 1.6$ & $17.9 \pm 1.4$ & $20.4 \pm 1.7$ & $19.6 \pm 1.8$ \\
\hline C18:2n-6 (LA) & $3.65 \pm 0.2$ & $3.52 \pm 0.3$ & $3.12 \pm 0.2$ & $3.71 \pm 0.4$ \\
\hline C18:3n-3 (ALA) & $1.30 \pm 0.3^{c}$ & $1.27 \pm 0.2^{c}$ & $0.52 \pm 0.05^{\mathrm{a}, \mathrm{b}, \mathrm{d}}$ & $1.11 \pm 0.1^{c}$ \\
\hline C20:4n-6 (AA) & $17.1 \pm 1.2^{c}$ & $17.8 \pm 1.4^{c}$ & $11.7 \pm 0.7^{a, b, d}$ & $15.9 \pm 1.6^{c}$ \\
\hline C20:5n-3 (EPA) & $0.82 \pm 0.04^{c}$ & $0.86 \pm 0.03^{c, d}$ & $0.51 \pm 0.02^{a, b, d}$ & $0.76 \pm 0.05^{c}$ \\
\hline C22:5n-6 (DPAn-6) & $0.30 \pm 0.05^{c, d}$ & $0.26 \pm 0.05^{c, d}$ & $1.33 \pm 0.08^{a, b, d}$ & $1.10 \pm 0.04^{a, b, c}$ \\
\hline C22:5n-3 (DPAn-3) & $0.45 \pm 0.04^{c}$ & $0.49 \pm 0.05^{c, d}$ & $0.24 \pm 0.02^{a, b, d}$ & $0.42 \pm 0.03^{b, d}$ \\
\hline C22:6n-3 (DHA) & $11.5 \pm 1.2^{c}$ & $12.3 \pm 1.4^{c}$ & $7.02 \pm 0.6^{a, b, d}$ & $10.9 \pm 1.5^{c}$ \\
\hline Total SFAs & $42.5 \pm 3.1^{c}$ & $40.8 \pm 2.9^{c}$ & $52.8 \pm 3.8^{\mathrm{a}, \mathrm{b}, \mathrm{d}}$ & $43.8 \pm 3.3^{c}$ \\
\hline Total MUFAs & $21.7 \pm 1.9$ & $20.6 \pm 1.7$ & $22.5 \pm 1.5$ & $21.2 \pm 2.0$ \\
\hline Total PUFAs & $35.8 \pm 2.8^{c}$ & $38.6 \pm 3.0^{c}$ & $24.7 \pm 2.1^{a, b, d}$ & $35.0 \pm 3.1^{c}$ \\
\hline Total LCPUFAs & $30.5 \pm 2.3^{c}$ & $32.6 \pm 2.9^{c}$ & $21.0 \pm 1.8^{\mathrm{a}, \mathrm{b}, \mathrm{d}}$ & $29.5 \pm 2.5^{c}$ \\
\hline Total n-6 LCPUFAs & $17.6 \pm 1.3^{c}$ & $18.4 \pm 1.4^{c}$ & $13.2 \pm 1.0^{\mathrm{a}, \mathrm{b}, \mathrm{d}}$ & $17.3 \pm 1.4^{c}$ \\
\hline Total n-3 LCPUFAs & $12.9 \pm 1.0^{c}$ & $14.2 \pm 1.1^{c}$ & $7.80 \pm 0.4^{a, b, d}$ & $12.2 \pm 0.8^{c}$ \\
\hline n-6/n-3 LCPUFA ratio & $1.36 \pm 0.2$ & $1.29 \pm 0.2$ & $1.69 \pm 0.3$ & $1.41 \pm 0.2$ \\
\hline
\end{tabular}

Dietary supplementation with HT in animals fed a HFD achieved a significant reduction of metabolic disorders caused by the HFD, including the recovery of the desaturase activity of the liver and the LCPUFAs profile of liver and extrahepatic tissues, the prevention of the damage induced by oxidative stress being one of the most important benefits that can be outlined (Fig. 3). In this regard, the antioxidant properties derived from the HT has proven to exert effective hepatoprotection, either against lipid peroxidation, liver steatosis, ischemia/reperfusion injury, and inflammation $[19,55,56]$. Moreover, HT restored the intestinal barrier integrity and functions in mice fed high fat diet [55]. It is also possible that HT can modulate the absorption of lipids in the intestine, especially cholesterol [57], but this effect still requires further investigation. HT-induced enhancement in the antioxidative potential of the liver seems to be associated with activation of nuclear factor-erythroid related factor 2 (Nrf2), a transcription factor controlling the expression of SOD, CAT, GR, and GPX (Fig. 3), besides that of glutathione-S-transferase and detoxicant enzymes [58-61], with recovery of the glutathione status presumably being related to upregulation of the biosynthetic enzymes of the tripeptide. These redox-mediated protective effects of HT are complemented by reductions in SREBP-1c expression, mitochondrial abnormalities, and apoptosis [19], besides diminution of ER stress induced by tunicamycin in human liver cells [62], with suppression of cell growth in human hepatocellular carcinoma cells via inactivation of AKT and nuclear factor- $\mathrm{kB}$ (NF- $\mathrm{kB}$ ) pathways [63]. The protective effects of HT are not restricted to the liver as this polyphenol relieves brain damage produced by subarachnoid hemorrhage in rats by preventing oxidative stress and reducing the activity of NF- $\mathrm{KB}$ [64], effects that are also evident in the prevention of neuronal damage induced by dopamine and 6-hydroxydopamine through an enhanced expression of phase II-detoxification enzymes such as NADPH quinone oxidoreductase 1 [65].

\section{Conclusions}

Dietary supplementation with HT mitigates the deleterious metabolic effects produced by HFD in mice. Protective effects of HT in the liver are associated to (i) the recovery of the activity of $\Delta-5$ and $\Delta-6$ desaturase enzymes, with 
Table 5 Fatty acid composition of heart phospholipids from control mice and high-fat diet (HFD) fed mice receiving hydroxytyrosol (HT) supplementation

\begin{tabular}{|c|c|c|c|c|}
\hline \multirow[b]{5}{*}{ Fatty acid } & \multicolumn{4}{|c|}{ Fatty acid composition (g/100 g FAME) } \\
\hline & \multicolumn{4}{|l|}{ Groups } \\
\hline & \multicolumn{2}{|c|}{ Control diet (CD) } & \multicolumn{2}{|c|}{ High fat diet (HFD) } \\
\hline & Saline & HT & Saline & HT \\
\hline & (a) & (b) & (c) & (d) \\
\hline C16:0 & $33.5 \pm 2.9^{c}$ & $32.8 \pm 3.0^{c}$ & $42.9 \pm 3.4^{\mathrm{a}, \mathrm{b}, \mathrm{d}}$ & $34.7 \pm 2.7^{c}$ \\
\hline $\mathrm{C} 18: 0$ & $4.84 \pm 0.3$ & $4.32 \pm 0.5$ & $3.94 \pm 0.3$ & $5.11 \pm 0.5$ \\
\hline C18:1n-9 & $22.8 \pm 2.3$ & $23.9 \pm 2.5$ & $22.4 \pm 1.9$ & $23.3 \pm 2.7$ \\
\hline C18:2n-6 (LA) & $11.7 \pm 1.5$ & $11.6 \pm 1.3$ & $11.9 \pm 1.6$ & $12.5 \pm 1.2$ \\
\hline C18:3n-3 (ALA) & $1.36 \pm 0.1^{c, d}$ & $1.44 \pm 0.1^{\mathrm{c}, \mathrm{d}}$ & $0.82 \pm 0.04^{\mathrm{a}, \mathrm{b}, \mathrm{d}}$ & $1.12 \pm 0.05^{\mathrm{a}, \mathrm{b}, \mathrm{c}}$ \\
\hline C20:4n-6 (AA) & $11.6 \pm 1.4$ & $10.8 \pm 1.2$ & $10.90 \pm 1.6$ & $11.3 \pm 1.7$ \\
\hline C20:5n-3 (EPA) & $2.82 \pm 0.1^{c, d}$ & $2.99 \pm 0.1^{\mathrm{c}, \mathrm{d}}$ & $0.98 \pm 0.04^{\mathrm{a}, \mathrm{b}, \mathrm{d}}$ & $1.53 \pm 0.05^{\mathrm{a}, \mathrm{b}, \mathrm{c}}$ \\
\hline C22:5n-6 (DPAn-6) & $0.68 \pm 0.1^{c}$ & $0.75 \pm 0.05^{c}$ & $0.35 \pm 0.02^{\mathrm{a}, \mathrm{b}, \mathrm{d}}$ & $0.62 \pm 0.04^{c}$ \\
\hline C22:5n-3 (DPAn-3) & $0.72 \pm 0.05^{\mathrm{c}}$ & $0.79 \pm 0.1^{c}$ & $0.28 \pm 0.01^{\mathrm{a}, \mathrm{b}, \mathrm{d}}$ & $0.67 \pm 0.05^{c}$ \\
\hline C22:6n-3 (DHA) & $5.15 \pm 0.3^{c}$ & $5.36 \pm 0.2^{c, d}$ & $2.05 \pm 0.1^{a, b, d}$ & $4.77 \pm 0.2^{b, c}$ \\
\hline Total SFAs & $39.3 \pm 3.3^{c}$ & $37.8 \pm 3.0^{c}$ & $47.9 \pm 4.1^{\mathrm{a}, \mathrm{b}, \mathrm{d}}$ & $40.3 \pm 3.8^{c}$ \\
\hline Total MUFAs & $25.6 \pm 2.6$ & $26.9 \pm 2.4$ & $24.4 \pm 2.2$ & $25.6 \pm 2.7$ \\
\hline Total PUFAs & $35.1 \pm 3.1^{c}$ & $35.3 \pm 3.3^{c}$ & $28.0 \pm 2.5^{a, b, d}$ & $34.1 \pm 3.2^{c}$ \\
\hline Total LCPUFAs & $21.3 \pm 1.8$ & $21.0 \pm 1.6$ & $14.8 \pm 0.5$ & $19.9 \pm 1.7$ \\
\hline Total n-6 LCPUFAs & $12.4 \pm 1.2$ & $11.7 \pm 1.1$ & $11.4 \pm 0.9$ & $12.4 \pm 1.3$ \\
\hline Total n-3 LCPUFAs & $8.90 \pm 0.5^{c, d}$ & $9.30 \pm 0.7^{c, d}$ & $3.40 \pm 0.2^{\mathrm{a}, \mathrm{b}, \mathrm{d}}$ & $7.50 \pm 0.3^{a, b, c}$ \\
\hline$n-6 / n-3$ LCPUFA ratio & $1.39 \pm 0.2^{c}$ & $1.26 \pm 0.2^{c}$ & $3.35 \pm 0.2^{a, b, d}$ & $1.65 \pm 0.3^{c}$ \\
\hline
\end{tabular}

Values are expressed as $\mathrm{g}$ fatty acid per $100 \mathrm{~g}$ FAME and represent the mean \pm SEM for $n=12-14$ mice per experimental group. Significant differences between the groups are indicated by the letter identifying each group (one-way ANOVA and Newman-Keuls' post-test; $p<0.05$ ). The identification of saturated and unsaturated fatty acids and their relationships are shown in Table 2

Table 6 Fatty acid composition of testicle phospholipids from control mice and high-fat diet (HFD) fed mice receiving hydroxytyrosol (HT) supplementation

\begin{tabular}{|c|c|c|c|c|}
\hline \multirow[b]{5}{*}{ Fatty acid } & \multicolumn{4}{|c|}{ Fatty acid composition (g/100 g FAME) } \\
\hline & \multicolumn{4}{|l|}{ Groups } \\
\hline & \multicolumn{2}{|c|}{ Control diet (CD) } & \multicolumn{2}{|c|}{ High fat diet (HFD) } \\
\hline & Saline & HT & Saline & HT \\
\hline & (a) & (b) & (c) & (d) \\
\hline $\mathrm{C16:0}$ & $30.6 \pm 3.0^{c}$ & $29.2 \pm 2.7^{c}$ & $41.6 \pm 3.9^{\mathrm{a}, \mathrm{b}, \mathrm{d}}$ & $29.5 \pm 2.9^{c}$ \\
\hline C18:0 & $7.51 \pm 1.2$ & $6.99 \pm 0.8$ & $6.21 \pm 1.1$ & $7.44 \pm 0.9$ \\
\hline C18:1n-9 & $22.6 \pm 2.0$ & $23.9 \pm 2.4$ & $21.8 \pm 1.9$ & $24.5 \pm 2.6$ \\
\hline C18:2n-6 (LA) & $11.6 \pm 0.6$ & $12.8 \pm 0.9$ & $10.6 \pm 0.6$ & $11.2 \pm 0.5$ \\
\hline C18:3n-3 (ALA) & $2.06 \pm 0.2^{c}$ & $2.21 \pm 0.2^{c}$ & $0.56 \pm 0.05^{a, b, d}$ & $1.98 \pm 0.1^{c}$ \\
\hline C20:4n-6 (AA) & $8.54 \pm 0.7$ & $9.05 \pm 0.9$ & $8.40 \pm 0.8$ & $8.38 \pm 0.7$ \\
\hline C20:5n-3 (EPA) & $1.19 \pm 0.2^{c}$ & $1.36 \pm 0.1^{c}$ & $0.46 \pm 0.05^{\mathrm{a}, \mathrm{b}, \mathrm{d}}$ & $1.25 \pm 0.2^{c}$ \\
\hline C22:5n-6 (DPAn-6) & $0.38 \pm 0.06^{c}$ & $0.45 \pm 0.07^{c}$ & $0.12 \pm 0.03^{a, b, d}$ & $0.41 \pm 0.06^{\circ}$ \\
\hline C22:5n-3 (DPAn-3) & $0.44 \pm 0.05^{c}$ & $0.49 \pm 0.06^{c}$ & $0.15 \pm 0.02^{a, b, d}$ & $0.43 \pm 0.07^{\circ}$ \\
\hline $\mathrm{C} 22: 6 n-3(\mathrm{DHA})$ & $10.2 \pm 1.1^{c}$ & $10.6 \pm 1.4^{c}$ & $4.58 \pm 0.8^{\mathrm{a}, \mathrm{b}, \mathrm{d}}$ & $9.36 \pm 1.2^{c}$ \\
\hline Total SFAs & $38.9 \pm 3.3^{c}$ & $36.8 \pm 3.1^{c}$ & $48.2 \pm 4.1^{\mathrm{a}, \mathrm{b}, \mathrm{d}}$ & $38.4 \pm 3.4^{c}$ \\
\hline Total MUFAs & $25.7 \pm 2.5$ & $26.6 \pm 2.2$ & $24.9 \pm 2.1$ & $27.6 \pm 2.4$ \\
\hline Total PUFAs & $35.4 \pm 3.1^{c}$ & $36.6 \pm 3.4^{c}$ & $26.9 \pm 2.2^{a, b, d}$ & $34.0 \pm 3.0^{c}$ \\
\hline Total LCPUFAs & $21.1 \pm 1.9^{c}$ & $22.5 \pm 2.2^{c}$ & $13.9 \pm 1.0^{\mathrm{a}, \mathrm{b}, \mathrm{d}}$ & $20.5 \pm 2.0^{c}$ \\
\hline Total n-6 LCPUFAs & $9.12 \pm 0.8$ & $9.70 \pm 0.9$ & $8.70 \pm 0.7$ & $9.00 \pm 0.8$ \\
\hline Total n-3 LCPUFAs & $11.9 \pm 1.1^{c}$ & $12.8 \pm 1.4^{c}$ & $5.20 \pm 0.5^{a, b, d}$ & $11.5 \pm 0.9^{c}$ \\
\hline$n-6 / n-3$ LCPUFA ratio & $0.77 \pm 0.05^{c}$ & $0.76 \pm 0.04^{c}$ & $1.67 \pm 0.3^{\mathrm{a}, \mathrm{b}, \mathrm{d}}$ & $0.78 \pm 0.04$ \\
\hline
\end{tabular}

Values are expressed as g fatty acid per $100 \mathrm{~g}$ FAME and represent the mean \pm SEM for $n=12-14$ mice per experimental group. Significant differences between the groups are indicated by the letter identifying each group (one-way ANOVA and Newman-Keuls' post-test; $p<0.05$ ). The identification of saturated and unsaturated fatty acids and their relationships are shown in Table 2 
prevention of n-3 LCPUFAs depletion, (ii) a reduction in the oxidative stress status; (iii) downregulation of the lipogenic factor SREBP-1c; and (iv) the maintenance of the levels of n-3 LCPUFAs in extrahepatic tissues. In this respect, it was hypothesized that n-3 LCPUFA-aspirin combined protocols may improve the management of sepsis and acute respiratory distress syndrome, due to the n-3 LCPUFA-derived resolvins generation that are potent antiinflammatory mediators [66]. In regard to the dose of HT used in our study $(5 \mathrm{mg} / \mathrm{kg} / \mathrm{day})$ and the protective effects generated in mice fed with HFD, other researchers have used higher levels of HT (10 mg/kg/day) [19, 56]. In the future, these aspects need more investigations. Data presented also demonstrate the importance of dietary interventions that consider supplementation with HT, particularly due to its antioxidant potential, observation that reinforces the importance of dietary interventions addressing oxidative stress prevention and n-3 LCPUFA tissue level preservation, thus strengthening the contention that many of the benefits associated to the consumption of EVOO may be associated to its content of HT [39].

\section{Additional file}

Additional file 1: Table S1. Composition of the experimental diets. Table S2. Gene specific primer sequences used in the study. (DOC $52 \mathrm{~kb}$ )

\begin{abstract}
Abbreviations
AA: Arachidonic acid; ALA: Alpha-linolenic acid; ALT: Alanine transaminase; AST: Aspartate transaminase; BHT: Butylated hydroxytoluene; CAT: Catalase; CD: Control diet; COX1: Cyclooxygenase 1; DHA: Docosahexaenoic acid; DHGLA: Dihomo-gamma-linolenic acid; EPA: Eicosapentaenoic acid; EVOO: Extra virgin olive oil; FAME: FA methyl esters; FAs: Fatty acids; FID: Flame ionization detector; GLA: Gamma-linolenic acid; GPX: Glutathione peroxidase; GR: Glutathione reductase; GSGG: Glutathione disulfide; GSH: Reduced glutathione; HFD: High-fat diet; HOMA: Homeostasis model assessment method; HT: Hydroxytyrosol; LA: Linoleic acid; LCPUFAs: Long-chain polyunsaturated fatty acids; NF-kB: Nuclear factor-kB; NO: Nitric oxide; Nrf2: Nuclear factor-erythroid related factor 2; PPAR- - : Peroxisome proliferatoractivated receptor- $\gamma ;$ PUFA: Polyunsaturated fatty acids; ROS: Reactive oxygen species; SOD: Superoxide dismutase; SREBP1c: Sterol regulatory element-binding protein 1c; TBARs: Thiobarbituric acid reactants; TLC: Thin layer chromatography
\end{abstract}

\section{Acknowledgments}

Authors are grateful to FONDECYT (National Fund for Scientific and Technological Development) Grant 11140174 (granted to R. V.), for supporting this study.

\section{Funding}

The study work was completed with the support of FONDECYT (National Fund for Scientific and Technological Development) Grant 11140174.

\section{Availability of data and materials}

All data generated or analysed during this study are included in this published article [and its Additional file].

\section{Authors' contributions}

Conceived and designed the experiments: RV and LV. Performed the experiments: RV, FE, MO, AE and MCH-R. Analyzed the data: RV, MAR, AV and LV. Contributed reagents/materials/analysis tools: AV and MAR. Wrote the paper: RV, AV and LV. All authors read and approved the final manuscript.

\section{Competing interest}

The authors declare that they have no competing interests.
Consent for publication

Not applicable

\section{Ethics approval}

Experimental animal protocols and animal procedures complied with the Guide for the Care and Use of Laboratory Animals (National Academy of Sciences, NIH Publication 6-23, revised 1985) and were approved by the Bioethics Committee for Research in Animals, Faculty of Medicine, University of Chile (protocol CBA\#CBA0667FMUCH)

\section{Publisher's Note}

Springer Nature remains neutral with regard to jurisdictional claims in published maps and institutional affiliations.

\section{Author details}

${ }^{1}$ Nutrition Department, Faculty of Medicine, University of Chile, Independencia 1027, Casilla, 70000 Santiago 7, Chile. ${ }^{2}$ Lipid Center, Institute of Nutrition and Food Technology (INTA), University of Chile, Santiago, Chile. ${ }^{3}$ Medical Technology Department, Faculty of Medicine, University of Chile, Santiago, Chile. ${ }^{4}$ Biochemistry Department. Faculty of Biochemistry, University of Litoral, Santa Fe, Argentina. ${ }^{5}$ Molecular and Clinical Pharmacology Program, Institute of Biomedical Science, Faculty of Medicine, University of Chile, Santiago, Chile.

Received: 22 January 2017 Accepted: 9 March 2017

Published online: 11 April 2017

\section{References}

1. Nakamura MT, Nara TY. Essential fatty acid synthesis and its regulation in mammals. Prostaglandins Leukot Essent Fatty Acids. 2003;68:145-50.

2. Choque B, Catheline D, Delplanque B, Guesnet P, Legrand P. Dietary linoleic acid requirements in the presence of a-linolenic acid are lower than the historical 2\% of energy intak e value, study in rats. Br J Nutr. 2015;113:1056-68.

3. Leonard AE, Pereira SL, Sprecher H, Huang YS. Elongation of long-chain fatty acids. Prog Lipid Res. 2004;43:36-54.

4. Brenna JT. Arachidonic acid needed in infant formula when docosahexaenoic acid is present. Nutr Rev. 2016;74:329-36.

5. Barceló-Coblijn G, Murphy EJ. Alpha-linolenic acid and its conversion to longer chain n-3 fatty acids: benefits for human health and a role in maintaining tissue n-3 fatty acid levels. Prog Lipid Res. 2009;48:355-74.

6. Mozaffarian D, Wu JH. (n-3) Fatty acids and cardiovascular health: are effects of EPA and DHA shared or complementary? J Nutr. 2012;142:614S-25.

7. Luxwolda MF, Kuipers RS, Sango WS, Kwesigabo G, Dijck-Brouwer DA, Muskiet FA. A maternal erythrocyte DHA content of approximately $6 \mathrm{~g} \%$ is the DHA status at which intrauterine DHA biomagnifications turns into bioattenuation and postnatal infant DHA equilibrium is reached. Eur J Nutr. 2012;51:665-75

8. Otaegui-Arrazola A, Amiano P, Elbusto A, Urdaneta E, Martínez-Lage P. Diet, cognition, and Alzheimer's disease: food for thought. Eur J Nutr. 2014;53:1-23.

9. Rincón-Cervera MA, Valenzuela R, Hernandez-Rodas MC, et al. Vegetable oils rich in alpha linolenic acid increment hepatic n-3 LCPUFA, modulating the fatty acid metabolism and antioxidant response in rats. Prostaglandins Leukot Essent Fatty Acids. 2016;111:25-35.

10. Nakamura MT, Nara TY. Structure, function, and dietary regulation of delta6, delta5, and delta9 desaturases. Annu Rev Nutr. 2004;24:345-76.

11. Vaittinen $M$, Walle $P$, Kuosmanen $E$, et al. FADS2 genotype regulates delta-6 desaturase activity and inflammation in human adipose tissue. J Lipid Res. 2016;57:56-65.

12. Meesapyodsuk D, Qiu X. The front-end desaturase: structure, function, evolution and biotechnological use. Lipids. 2012;47:227-37.

13. Koletzko B, Lattka E, Zeilinger S, Illig T, Steer C. Genetic variants of the fatty acid desaturase gene cluster predict amounts of red blood cell docosahexaenoic and other polyunsaturated fatty acids in pregnant women: findings from the Avon longitudinal study of parents and children. Am J Clin Nutr. 2011;93:211-9.

14. Araya J, Rodrigo R, Pettinelli P, et al. "Decreased liver fatty acid delta-6 and delta-5 desaturase activity in obese patients. Obesity. 2010;18:1460-3.

15. Valenzuela R, Barrera C, Espinosa A, et al. Reduction in the desaturation capacity of the liver in mice subjected to high fat diet: Relation to LCPUFA depletion in liver and extrahepatic tissues. Prostaglandins Leukot Essent Fatty Acids. 2015;98:7-14. 
16. Cicerale S, Lucas LJ, Keast RS. Antimicrobial, antioxidant and antiinflammatory phenolic activities in extra virgin olive oil. Curr Opin Biotechnol. 2012;23:129-35.

17. Vilaplana-Pérez C, Auñón D, García-Flores LA, Gil-Izquierdo A. Hydroxytyrosol and potential uses in cardiovascular diseases, cancer, and AIDS. Front Nutr. 2014:27:1-18.

18. Catalán U, López de Las Hazas MC, Rubió L, et al. Protective effect of hydroxytyrosol and its predominant plasmatic human metabolites against endothelial dysfunction in human aortic endothelial cells. Mol Nutr Food Res. 2015;59:2523-36.

19. Cao K, Xu J, Zou X, et al. Hydroxytyrosol prevents diet-induced metabolic syndrome and attenuates mitochondrial abnormalities in obese mice. Free Radic Biol Med. 2014:67:396-407.

20. Scoditti E, Nestola A, Massaro M, et al. Hydroxytyrosol suppresses MMP-9 and COX-2 activity and expression in activated human monocytes via PKCa and PKC 31 inhibition. Atherosclerosis. 2014;232:17-24.

21. Zrelli H, Matsuoka M, Kitazaki S, et al. Hydroxytyrosol induces proliferation and cytoprotection against oxidative injury in vascular endothelial cells: role of Nrf2 activation and HO-1 induction. J Agric Food Chem. 2011;59:4473-82.

22. Brunt EM, Janney CG, Di Bisceglie AM, et al. Nonalcoholic steatohepatitis: a proposal for grading and staging the histological lesions. Am J Gastroenterol. 1999;94:2467-74.

23. Matthews DR, Hosker JP, Rudenski AS, et al. Homeostasis model assessment: insulin resistance and beta-cell function from fasting plasma glucose and insulin concentrations in man. Diabetologia. 1985;28:412-9.

24. Rahman I, Kode A, Biswas SK. Assay for quantitative determination of glutathione and glutathione disulfide levels using enzymatic recycling method. Nat Protoc. 2006;1:3159-65.

25. Su HM, Brenna JT. Simultaneous measurement of desaturase activities using stable isotope tracers or a nontracer method. Anal Biochem. 1998;261:43-50.

26. Valenzuela R, Barrera C, González-Astorga M, Sanhueza J, Valenzuela A. Alpha linolenic acid (ALA) from Rosa canina, sacha inchi and chia oils may increase ALA accretion and its conversion into n-3 LCPUFA in diverse tissues of the rat. Food Funct. 2014;5:1564-72.

27. Chow CK, Reddy K, Tappel AL. Effect of dietary vitamin E on the activities of the glutathione peroxidase system in rat tissues. J Nutr. 1973;103:618-24.

28. Aebi H. Catalase. In: Bergmeyer HU, editor. Methods of Enzymatic Analysis, vol. 2. New York: Academic; 1965. p. 673-84.

29. Paglia DE, Valentine WN. Studies on the quantitative and qualitative characterization of erythrocyte glutathione peroxidase. J Lab Clin Med. 1967; 70:158-69.

30. Horn MD. In: Bergmeyer HU, editor. Methods of Enzymatic Assays, vol. 2. New York: Academic; 1963. p. 875-9.

31. Bligh EG, Dyer WJ. A rapid method of total lipid extraction and purification. Can J Biochem Physiol. 1959;37:911-7.

32. Ruiz-Gutierrez V, Cert A, Rios JJ. Determination of phospholipid fatty acid and triacylglycerol composition of rat caecal mucosa. J Chromatogr. 1992;575:1-6.

33. Morrison WR, Smith LM. Preparation of fatty acid methyl esters and dimethylacetals from lipids with boron fluoride-methanol. J Lipid Res. 1964;5:600-8.

34. Domenichiello AF, Kitson AP, Bazinet RP. Is docosahexaenoic acid synthesis from a-linolenic acid sufficient to supply the adult brain? Prog Lipid Res. 2015;59:54-66

35. Eder K, Kirchgessner M. Activities of liver microsomal fatty acid desaturases in zinc-deficient rats force-fed diets with a coconut oil/safflower oil mixture of linseed oil. Biol Trace Elem Res. 1995;48:215-29.

36. Nakamura MT, Tang AB, Villanueva J, Halsted CH, Phinney SD. Selective reduction of delta 6 and delta 5 desaturase activities but not delta 9 desaturase in micropigs chronically fed ethanol. J Clin Investig. 1994;93:450-4.

37. Glaser C, Heinrich J, Koletzko B. Role of FADS1 and FADS2 polymorphisms in polyunsaturated fatty acid metabolism. Metabolism. 2010;59:993-9.

38. Araya J, Rodrigo R, Videla LA, et al. Increase in long-chain polyunsaturated fatty acid $n-6 / n-3$ ratio in relation to hepatic steatosis in patients with non-alcoholic fatty liver disease. Clin Sci. 2004;106:635-43.

39. Rincón-Cervera MA, Valenzuela R, Hernandez-Rodas MC, et al. Supplementation with extra virgin olive oil rich in antioxidants prevents hepatic oxidative stress and reduction of desaturation capacity in mice fed high fat diet: effects on fatty acid composition in liver and extra hepatic tissues. Nutrition. 2016:418:1254-67.

40. Osman RH, Liu L, Xia L, et al. Fads1 and 2 are promoted to meet instant need for long-chain polyunsaturated fatty acids in goose fatty liver. Mol Cell Biochem. 2016;418:103-17.
41. Shang F, Taylor A. Ubiquitin-proteasome pathway and cellular responses to oxidative stress. Free Radic Biol Med. 2011:51:5-16.

42. Videla LA, Fernández V, Cornejo P, et al. Causal role of oxidative stress in unfolded protein response development in the hyperthyroid state. Free Radic Biol Med. 2015;89:401-8.

43. Nissar AU, Sharma L, Tasduq SA. Palmitic acid induced lipotoxicity is associated with altered lipid metabolism, enhanced CYP450 2E1 and intracellular calcium mediated ER tress in human hepatoma cells. Toxicology Research. 2015;4:1344-58.

44. Nakamura MT, Nara TY. Gene regulation of mammalian desaturases. Biochem Soc Trans. 2002;30:076-1079.

45. Zheng Z, Zhang C, Zhang K. Role of unfolded protein response in lipogenesis. World J Hepatol. 2010;2:203-7.

46. Gu Q, Yang X, Lin L, Li S, et al. Genetic ablation of solute carrier family 7a3a leads to hepatic steatosis in zebrafish during fasting. Hepatology. 2014;60:1929-41.

47. Elizondo A, Araya J, Rodrigo R, et al. Polyunsaturated fatty acid pattern in liver and erythrocyte phospholipids from obese patients. Obesity. 2007:15:24-31.

48. Bazinet RP, Layé S. Polyunsaturated fatty acids and their metabolites in brain function and disease. Nature Rev Neurosci. 2014;15:771-85.

49. Mozaffarian D, Wu JH. Omega-3 fatty acids and cardiovascular disease: effects on risk factors, molecular pathways, and clinical events. J Am Coll Cardiol. 2011;58:2047-67.

50. Arterburn LM, Hall EB, Oken H. Distribution, interconversion, and dose response of n-3 fatty acids in humans. Am J Clin Nutr. 2006;83:1467S-176S.

51. Safarinejad MR. Effect of omega-3 polyunsaturated fatty acid supplementation on semen profile and enzymatic anti-oxidant capacity of seminal plasma in infertile men with idiopathic oligoasthenoteratospermia: a double-blind, placebo-controlled, randomised study. Andrologia. 2011;43:38-47.

52. Safarinejad MR, Hosseini SY, Dadkhah F, Asgari MA. Relationship of omega-3 and omega- 6 fatty acids with semen characteristics, and anti-oxidant status of seminal plasma: a comparison between fertile and infertile men. Clin Nutr. 2010;29:100-5.

53. Domenichiello AF, Kitson AP, Chen $C T$, et al. The effect of linoleic acid on the whole body synthesis rates of polyunsaturated fatty acids from alinolenic acid and linoleic acid in free-living rats. J Nutr Biochem. 2016;30: 167-76.

54. Domenichiello AF, Chen CT, Trepanier MO, et al. Whole body synthesis rates of DHA from a-linolenic acid are greater than brain DHA accretion and uptake rates in adult rats. J Lipid Res. 2014;55:62-74.

55. Jemai H, El Feki A, Sayadi S. Antidiabetic and antioxidant effects of hydroxytyrosol and oleuropein from olive leaves in alloxan-diabetic rats. J Agric Food Chem. 2009;57:8798-904.

56. Pirozzi C, Lama A, Simeoli R, et al. Hydroxytyrosol prevents metabolic impairment reducing hepatic inflammation and restoring duodenal integrity in a rat model of NAFLD. J Nutr Biochem. 2016;30:108-15.

57. Kalaiselvan I, Samuthirapandi M, Govindaraju A, Sheeja Malar D, Kasi PD. Olive oil and its phenolic compounds (hydroxytyrosol and tyrosol) ameliorated TCDD-induced hepatotoxicity in rats via inhibition of oxidative stress and apoptosis. Pharm Biol. 2016;54:338-46.

58. Jemai H, Fki I, Bouaziz M, et al. Lipid-lowering and antioxidant effects of hydroxytyrosol and its triacetylated derivative recovered from olive tree leaves in cholesterol-fed rats. J Agric Food Chem. 2008;56:2630-6.

59. Pan $S$, Liu L, Pan $H$, et al. Protective effects of hydroxytyrosol on liver ischemia/reperfusion injury in mice. Mol Nutr Food Res. 2013;57:1218-27.

60. Tutino V, Caruso MG, Messa C, Perri E, Notarnicola M. Antiproliferative, antioxidant and anti-inflammatory effects of hydroxytyrosol on human hepatoma HepG2 and Hep3B cell lines. Anticancer Res. 2012;32:5371-7.

61. Martín MA, Ramos S, Granado-Serrano AB, et al. Hydroxytyrosol induces antioxidant/detoxificant enzymes and Nrf2 translocation via extracellular regulated kinases and phosphatidylinositol-3-kinase/protein kinase B pathways in HepG2 cells. Mol Nutr Food Res. 2010;54:956-66.

62. Giordano E, Davalos A, Nicod N, Visioli F. Hydroxytyrosol attenuates tunicamycin-induced endoplasmic reticulum stress in human hepatocarcinoma cells. Mol Nutr Food Res. 2014;58:954-62.

63. Zhao B, Ma Y, Xu Z, et al. Hydroxytyrosol, a natural molecule from olive oil, suppresses the growth of human hepatocellular carcinoma cells via inactivating AKT and nuclear factor-kappa B pathways. Cancer Lett. 2014;347:79-87. 
64. Fu P, Hu Q. 3,4-Dihydroxyphenylethanol alleviates early brain injury by modulating oxidative stress and Akt and nuclear factor-KB pathways in a rat model of subarachnoid hemorrhage. Exp Ther Med. 2016;11:1999-2004.

65. Yu G, Deng A, Tang W, et al. Hydroxytyrosol induces phase II detoxifying enzyme expression and effectively protects dopaminergic cells against dopamine- and 6-hydroxydopamine induced cytotoxicity. Neurochem Int. 2016;96:113-20

66. Das UN. Combination of aspirin with essential fatty acids is superior to aspirin alone to prevent or ameliorate sepsis or ARDS. Lipids Health Dis. 2016;15:1-8

Submit your next manuscript to BioMed Central and we will help you at every step:

- We accept pre-submission inquiries

- Our selector tool helps you to find the most relevant journal

- We provide round the clock customer support

- Convenient online submission

- Thorough peer review

- Inclusion in PubMed and all major indexing services

- Maximum visibility for your research

Submit your manuscript at www.biomedcentral.com/submit
Biomed Central 